\title{
Regulators of SIc4 bicarbonate transporter activity
}

\section{OPEN ACCESS}

Edited by:

Mauricio Antonio Retamal,

Universidad del Desarrollo, Chile

Reviewed by:

Ira Kurtz,

University of California, Los Angeles,

USA

Harpreet Singh,

Drexel University College of Medicine,

USA

Antonius Baartscheer, Academic Medical Center,

Netherlands

*Correspondence:

Mark O. Bevensee,

Department of Cell, Developmental and Integrative Biology, University of Alabama at Birmingham, 1720 2nd Ave. S, 812 MCLM, 1918 University Blvd., Birmingham, AL 35294-0005,

USA

bevensee@uab.edu

${ }^{\dagger}$ Present Address:

Ian M. Thornell, Michael J. Welsh Laboratory, Department of Internal Medicine, Howard Hughes Medical Institute, University of lowa, lowa City,

Specialty section:

This article was submitted to Membrane Physiology and Membrane Biophysics, a section of the journal Frontiers in Physiology

Received: 26 January 2015 Accepted: 15 May 2015 Published: 12 June 2015

Citation: Thornell IM and Bevensee MO (2015) Regulators of Slc4 bicarbonate transporter activity.

Front. Physiol. 6:166. doi: 10.3389/fphys.2015.00166

\author{
Ian M. Thornell ${ }^{1 \dagger}$ and Mark O. Bevensee ${ }^{1,2,3,4 *}$
}

'Department of Cell, Developmental and Integrative Biology, University of Alabama at Birmingham, Birmingham, AL, USA, ${ }^{2}$ Nephrology Research and Training Center, University of Alabama at Birmingham, Birmingham, AL, USA, ${ }^{3}$ Center of Glial Biology in Medicine, University of Alabama at Birmingham, Birmingham, AL, USA, ${ }^{4}$ Civitan International Research Center, University of Alabama at Birmingham, Birmingham, AL, USA

The S/c4 family of transporters is comprised of anion exchangers (AE1-4), $\mathrm{Na}^{+}$-coupled bicarbonate transporters (NCBTs) including electrogenic Na/bicarbonate cotransporters (NBCe1 and NBCe2), electroneutral $\mathrm{Na} /$ bicarbonate cotransporters (NBCn1 and $\mathrm{NBCn} 2$ ), and the electroneutral $\mathrm{Na}$-driven $\mathrm{Cl}$-bicarbonate exchanger (NDCBE), as well as a borate transporter (BTR1). These transporters regulate intracellular $\mathrm{pH}\left(\mathrm{pH}_{\mathrm{i}}\right)$ and contribute to steady-state $\mathrm{pH}_{\mathrm{i}}$, but are also involved in other physiological processes including $\mathrm{CO}_{2}$ carriage by red blood cells and solute secretion/reabsorption across epithelia. Acid-base transporters function as either acid extruders or acid loaders, with the Slc4 proteins moving $\mathrm{HCO}_{3}^{-}$either into or out of cells. According to results from both molecular and functional studies, multiple Slc4 proteins and/or associated splice variants with similar expected effects on $\mathrm{pH}_{\mathrm{i}}$ are often found in the same tissue or cell. Such apparent redundancy is likely to be physiologically important. In addition to regulating $\mathrm{pH}_{\mathrm{i}}$, a $\mathrm{HCO}_{3}^{-}$transporter contributes to a cell's ability to fine tune the intracellular regulation of the cotransported/exchanged ion(s) (e.g., $\mathrm{Na}^{+} \mathrm{or}^{-} \mathrm{Cl}^{-}$). In addition, functionally similar transporters or splice variants with different regulatory profiles will optimize $\mathrm{pH}$ physiology and solute transport under various conditions or within subcellular domains. Such optimization will depend on activated signaling pathways and transporter expression profiles. In this review, we will summarize and discuss both well-known and more recently identified regulators of the Slc4 proteins. Some of these regulators include traditional second messengers, lipids, binding proteins, autoregulatory domains, and less conventional regulators. The material presented will provide insight into the diversity and physiological significance of multiple members within the S/c4 gene family.

Keywords: acid-base, anion exchanger, cotransporter, pH, signaling

\section{Introduction}

The Solute carrier 4 (Slc4) gene products are part of a family of bicarbonate transporters (BTs) that include $\mathrm{Na}^{+}$-independent anion exchangers (AEs), as well as $\mathrm{Na}^{+}$-coupled bicarbonate transporters (NCBTs). NCBTs are further categorized into (i) $\mathrm{Na} /$ bicarbonate cotransporters (NBCs) that are either electrogenic (NBCe1 and $\mathrm{NBCe} 2)$ or electroneutral ( $\mathrm{NBCn} 1$ and $\mathrm{NBCn} 2$ ), and (ii) the electroneutral Na-driven Cl-bicarbonate exchanger (NDCBE). BTs regulate intracellular $\mathrm{pH}\left(\mathrm{pH}_{\mathrm{i}}\right)$ and can alter extracellular $\mathrm{pH}\left(\mathrm{pH}_{\mathrm{o}}\right)$ by functioning as either acid loaders 
that transport $\mathrm{HCO}_{3}^{-}$(or $\mathrm{CO}_{3}^{2-}$ ) out of cells, or acid extruders that transport these ions into cells.

BTs also contribute to the cellular homeostasis of other ions and associated properties in addition to $\mathrm{H}^{+}$and $\mathrm{HCO}_{3}^{-}$. For example, the $\mathrm{Cl}-\mathrm{HCO}_{3}$ exchanger $\left(\mathrm{Cl}^{-}\right.$into cells, $\mathrm{HCO}_{3}^{-}$out $)$ can act in concert with the $\mathrm{Na}-\mathrm{H}$ exchanger $\left(\mathrm{Na}^{+}\right.$in, $\mathrm{H}^{+}$out $)$ to move net $\mathrm{NaCl}$ into cells, thereby increasing intracellular $\mathrm{Na}^{+}\left(\mathrm{Na}_{\mathrm{i}}^{+}\right)$and $\mathrm{Cl}^{-}\left(\mathrm{Cl}_{\mathrm{i}}^{-}\right)$, but with no net movement of acid-base equivalents. Activating this pair of transporters in shrunken cells promotes cellular water uptake in a process known as volume regulatory increase (Hallows and Knauf, 1994). As another example, NCBTs contribute to the regulation of $\mathrm{Na}_{\mathrm{i}}^{+}$and intracellular $\mathrm{Ca}^{2+}\left(\mathrm{Ca}_{\mathrm{i}}^{2+}\right)$, and can directly influence membrane excitability. Such regulation is particularly evident in the heart where there is both electroneutral NBC activity (Dart and Vaughan-Jones, 1992; Lagadic-Gossmann et al., 1992; Leem et al., 1999) and electrogenic NBC activity (Camilión de Hurtado et al., 1995, 1996; Aiello et al., 1998). During ischemia and subsequent reperfusion of the heart, Na-coupled acid-base transporters in myocytes that are activated by ischemiainduced intracellular acidosis can elevate $\mathrm{Na}_{\mathrm{i}}^{+}$, which in turn can decrease and even reverse the $\mathrm{Na}-\mathrm{Ca}$ exchanger, thereby elevating $\mathrm{Ca}_{\mathrm{i}}^{2+}$ and promoting $\mathrm{Ca}^{2+}$-mediated injury. Indeed, $\mathrm{NBC}$ activity contributes to the $\mathrm{pH}_{\mathrm{i}}$ recovery of heart cells with reperfusion following ischemia/hypoxia (Vandenberg et al., 1993; Schafer et al., 2000; van Borren et al., 2004; Ten Hove et al., 2005; De Giusti et al., 2011; Fantinelli et al., 2014), but can also promote damaging $\mathrm{Na}_{\mathrm{i}}^{+}$and $\mathrm{Ca}_{\mathrm{i}}^{2+}$ overload (Schafer et al., 2000; Ten Hove et al., 2005). An antibody reported to inhibit human-heart NBCe1-B can protect the systolic and diastolic functions of rat heart during reperfusion (Khandoudi et al., 2001). However, cardioprotection from NBC blockade is not always evident depending on experimental conditions (Ten Hove et al., 2005). Consistent with the findings by Khandoudi et al. (2001), an antibody targeting the third extracellular loop of NBCe1 that inhibits NBCe1-B (De Giusti et al., 2011) limited the infarct size and protected the systolic and diastolic functions of reperfused isolated rat hearts (Fantinelli et al., 2014). Curiously, the compound S0859, which inhibits multiple NCBTs in the heart (Ch'en et al., 2008), limited the infarct size, but did not protect the systolic and diastolic functions (Fantinelli et al., 2014). In addition to contributing to $\mathrm{pH}_{\mathrm{i}}$ and ion homeostasis, electrogenic NBC activity produces an outward current that contributes to the resting membrane potential of cardiac cells and can shorten the action potential duration (Aiello et al., 1998; Villa-Abrille et al., 2007; De Giusti et al., 2011).

BTs not only contribute to ion homeostasis and steadystate $\mathrm{pH}_{\mathrm{i}}$ of cells, but also promote solute secretion and/or reabsorption by epithelia. For example, NBCe1-A in the basolateral membrane of cells in the renal proximal tubule (Boron and Boulpaep, 1983) is responsible for up to $90 \% \mathrm{HCO}_{3}^{-}$ reabsorption by the kidney. Basolateral NBCe1-B contributes to $\mathrm{HCO}_{3}^{-}$secretion by the pancreas (Muallem and Loessberg, 1990). Apical NDCBE works in conjunction with the apical anion exchanger pendrin to account for thiazide-sensitive $\mathrm{NaCl}$ reabsorption in the cortical collecting duct of kidney (Leviel et al., 2010). BTs also have roles ancillary to $\mathrm{pH}_{\mathrm{i}}$ regulation and solute transport. For example, the erythrocyte AE1 (eAE1) is responsible for the chloride (Hamburger) shift in erythrocytes that facilitates $\mathrm{CO}_{2}$ carriage in the blood from systemic to lung capillaries. NCBTs such as NBCe1, NBCn1, and NDCBE elicit $\mathrm{pH}_{\mathrm{o}}$ shifts in the nervous system that can modulate neuronal firing (Chesler, 2003).

Key advances in understanding the molecular nature of BTs came when Kopito and Lodish (1985) first cloned the cDNA encoding an anion exchanger (eAE1), and Romero et al. (1997) first cloned the cDNA of a NCBT (NBCe1-A). From additional cloning studies of other BTs, it became apparent that each family member has multiple variants that arise from alternative promoters or splicing. Nearly all of the variability occurs within the cytoplasmic amino (N)- and/or carboxy (C)terminal domain(s) (Boron et al., 2009; Parker and Boron, 2013). These variable domains are potential targets for intracellular regulators that modulate specific transporter activity, thereby tightly controlling associated $\mathrm{HCO}_{3}^{-}$transport and $\mathrm{pH}_{\mathrm{i}}$ changes. A regulator can alter a BT's transport activity by changing either transport biophysics (i.e., $\mathrm{K}_{\mathrm{M}}$ and $\mathrm{V}_{\max }$ ), transporter expression, or perhaps transport stoichiometry. Consequently, BT activity can be optimized for a given cell type depending on the BTs expressed and the signaling pathways and regulators either present or activated. There is considerable interest in understanding how Slc4 family members and their variants are regulated, thereby providing insight into the role of these variants in normal and abnormal physiology.

In this review, we will present our current understanding of regulatory mechanisms of the cloned BTs. We will first briefly review the molecular physiology of BTs, with an emphasis on areas pertinent to cell signaling. We will then examine each family member with an emphasis on functional importance and specific modes of regulation.

\section{Molecular Physiology}

The BT family consists of 10 genes that encode Slc4 proteins, which can be divided into the following three groups: $\mathrm{Na}^{+}$-independent AEs, $\mathrm{Na}^{+}$-dependent anion exchangers (i.e., NCBTs), and a borate transporter. The AEs consist of AE1-4 (encoded by Slc4a1-3,9). AE1-3 are acid loaders that normally exchange $1 \mathrm{Cl}^{-}$into cells for $1 \mathrm{HCO}_{3}^{-}$out of cells. At least AE1 can also mediate sulfate $/ \mathrm{H}^{+}$cotransport (Milanick and Gunn, 1984) and oxalate/ $\mathrm{H}^{+}$cotransport (Jennings and Adame, 1996) in exchange for $1 \mathrm{Cl}^{-}$. The function of AE4 is not entirely clear, and there is evidence that the transporter may be $\mathrm{Na}^{+}$dependent (Parker and Boron, 2013).

The electrogenic NCBTs include NBCe1 (Slc4a4) and NBCe2 (Slc4a5). Electrogenic NBCs are typically reported to cotransport $1 \mathrm{Na}^{+}$and either 2 or $3 \mathrm{HCO}_{3}^{-}$. Recently however, it has been discovered that $\mathrm{CO}_{3}^{2-}$ instead of $2 \mathrm{HCO}_{3}^{-}$appears to be the transported species for NBCe1 (Lee et al., 2011; Moss et al., 2014). $\mathrm{CO}_{3}^{2-}$ transport into cells can have important consequences, and is predicted to lead to a rise in extracellular $\mathrm{P}_{\mathrm{CO} 2}$, as discussed for such transport in the brain (Grichtchenko and Chesler, 1994; Voipio, 1998; McAlear and Bevensee, 2004). This $\mathrm{P}_{\mathrm{CO} 2}$ increase occurs because extracellular $\mathrm{HCO}_{3}^{-}$is rapidly converted into more $\mathrm{CO}_{3}^{2-}$ and $\mathrm{H}^{+}(\mathrm{pK} \sim 10.4)$. However, because the $\mathrm{H}^{+}$ 
increase is disproportionately larger than the $\mathrm{HCO}_{3}^{-}$decrease, equilibration requires the two to react and form more $\mathrm{CO}_{2}$ and $\mathrm{H}_{2} \mathrm{O}$. This production of extracellular $\mathrm{CO}_{2}$ and its subsequent rapid diffusion may be a valuable route for efficiently removing acid equivalents from metabolically active tissue (Voipio, 1998). For a 1:3 $\mathrm{Na}: \mathrm{HCO}_{3}^{-}$stoichiometry, $\mathrm{CO}_{3}^{2-}$ likely transports with a single $\mathrm{HCO}_{3}^{-}$(Zhu et al., 2013). For transport into cells, the energetically favorable inward electrochemical gradient for $\mathrm{Na}^{+}$ drives transport.

The remaining NCBT members that complete the family are electroneutral. Slc4a7 encodes the electroneutral $\mathrm{Na} / \mathrm{HCO}_{3}$ cotransporter (NBCn1), which normally extrudes acid by cotransporting $1 \mathrm{Na}^{+}$and $1 \mathrm{HCO}_{3}^{-}$into cells. Slc4a8 encodes the $\mathrm{Na}$-driven $\mathrm{Cl}_{-} \mathrm{HCO}_{3}$ exchanger (NDCBE), which extrudes acid utilizing the electrochemical energy of $1 \mathrm{Na}^{+}$into cells to drive the exchange of $\mathrm{HCO}_{3}^{-}$into cells for $1 \mathrm{Cl}^{-}$out of cells. In the transport process, two intracellular acid equivalents are neutralized, and this is likely achieved by the transport of $1 \mathrm{CO}_{3}^{2-}$ (Grichtchenko and Boron, 2002). Slc4a10 encodes the electroneutral $\mathrm{Na} / \mathrm{HCO}_{3}$ cotransporter (NBCn2), which normally extrudes acid by cotransporting $1 \mathrm{Na}^{+}$and $1 \mathrm{HCO}_{3}^{-}$ into cells, but with an associated futile $\mathrm{Cl}^{-}$self-exchange (Parker et al., 2008; Damkier et al., 2010). In early literature, this transporter was named a $\mathrm{Na}$-driven $\mathrm{Cl}-\mathrm{HCO}_{3}$ exchanger (NCBE). The transport mode of $\mathrm{NBCn} 2$ (NCBE) appears complex with a $\mathrm{Cl}^{-}$dependence that may depend on transport direction, species of the transporter, and/or expression system (see Majumdar and Bevensee, 2010; Parker and Boron, 2013).

The remaining BT is the Slc4a11-encoded borate transporter, which is a $\mathrm{Na}^{+}$-coupled base transporter capable of $\mathrm{Na}-\mathrm{H}$ exchange in mammalian cells (Jalimarada et al., 2013; Ogando et al., 2013; Kao et al., 2014). This borate transporter, along with AE4 described above, are the least functionally understood of all the BTs.

Structural information is available for BTs, particularly for AE1, but also for NCBTs that are $28-34 \%$ homologous to AE1 (Romero et al., 2004; Parker and Boron, 2013). The Nterminal $40 \%$ of AE1 is the cytosolic domain involved in binding other proteins and regulators, whereas the remaining $60 \%$ of the protein is the C-terminal membrane domain involved in ion transport (Reithmeier et al., 1996). Based on considerable data from proteolysis, labeling, and mutagenesis studies, AE1 is predicted to have 14 transmembrane domains with most spanning the membrane, and the $\mathrm{N}$ and $\mathrm{C}$ termini located in the cytosol (Cordat and Reithmeier, 2014). Using similar approaches and mapping onto the predicted topology of AE1, investigators have developed similar models for NCBTs such as NBCe1 (Zhu et al., 2010a,b; Kurtz and Zhu, 2013a,b; Parker and Boron, 2013), although there are likely structural differences among these transporters (Zhu et al., 2010a; Parker and Boron, 2013). A challenge in the field is to identify the structural similarities - or perhaps core structure-of BTs, and then the structural differences that define their functional uniqueness.

An early $3 \mathrm{D}$ crystal structure of the C-terminal membrane domain of AE1 resolved to $20 \AA$ revealed a dimer that contains a cytoplasmic region that likely directs substrate to a membrane region for translocation across the membrane (Wang et al., 1994;
Reithmeier et al., 1996). The structure of the N-terminal cytosolic domain of eAE1 resolved to $2.6 \AA$ revealed an interlinking Nterminal dimerization site (Zhang et al., 2000), and a similar structure resolved to $2.1 \AA$ of this domain missing its disordered regions was obtained at neutral pH (Shnitsar et al., 2013). The subsequent crystal structure of the dimeric C-terminal membrane domain at $7.5 \AA$ supported these models, and also revealed a surprising similarity to the structure of the prokaryotic $\mathrm{ClC}$ chloride channel, which functions as a $\mathrm{Cl}-\mathrm{H}$ exchanger (Yamaguchi et al., 2010; Hirai et al., 2011). These proteins have an inverted structural repeat of 5 transmembrane domains that is common among other transporters from different gene families including the $\mathrm{Na} /$ leucine cotransporter LeuT. More recently, Barneaud-Rocca et al. (2013) reported a similar homology model of the membrane domain of AE1 based on the crystal structure of the bacterial uracil/H symporter UraA, and provided evidence that specific transmembrane domains (e.g., 3, 5, and 8) form the ion-translocation pathway (Barneaud-Rocca et al., 2013). Cordat and Reithmeier (2014) provide a more detailed review of the aforementioned structures of AE1. Although a high-resolution crystal structure has not been solved for any $\mathrm{NCBT}$, the $\mathrm{N}$ terminus of NBCe1-A resolved to $3 \AA$ reveals an interlinking $\mathrm{N}$-terminal dimerization site (Gill and Boron, 2006) similar to that for AE1. Because of the similarity between $\mathrm{AE} 1$ and NCBTs, the structures of $\mathrm{ClC}$ and UraA used to model AE1 will also be useful in developing structural models of NCBTs.

In this review, we focus on AE1, AE2, NBCe1, NBCn1, $\mathrm{NDCBE}$, and NBCn2 because their modes of regulation are the best characterized to date. Alper et al. (2002), Romero et al. (2004), Parker and Boron (2013), and Cordat and Reithmeier (2014) provide a more in-depth discussion of BT family members beyond the scope of regulation.

\section{AE1 (S/c4a1) and AE2 (S/c4a2)}

During the cloning era, one of the early cDNAs identified encoded the murine erythrocyte AE1 (eAE1) (Kopito and Lodish, 1985). eAE1 is commonly known as band 3 protein because it is the third band resolved when total erythrocyte protein is separated by gel electrophoresis. AE1 normally functions as an acid loader by exchanging 1 extracellular $\mathrm{Cl}^{-}$for 1 intracellular $\mathrm{HCO}_{3}^{-}$, but can transport in the opposite direction by changing the ion gradients (e.g., by removing extracellular $\mathrm{Cl}^{-}$) as described below for erythrocytes.

In erythrocytes, AE1 is an integral component of the JacobsStewart cycle, which is responsible for increasing the total $\mathrm{CO}_{2}$-carrying capacity of blood from the systemic circulation to the lungs, and allowing large amounts of this $\mathrm{CO}_{2}$ to be carried in the form of $\mathrm{HCO}_{3}^{-}$(Boron, 2012). In brief, about two-thirds of $\mathrm{CO}_{2}$ that enters the erythrocytes is hydrolyzed to $\mathrm{H}^{+}$and $\mathrm{HCO}_{3}^{-}-$mainly through the action of carbonic anhydrase (CA). eAE1-mediated $\mathrm{Cl}-\mathrm{HCO}_{3}$ exchange, which is also known as the $\mathrm{Cl}^{-}$or Hamburger shift, prevents the ratelimiting accumulation of intracellular $\mathrm{HCO}_{3}^{-}$by transporting the $\mathrm{HCO}_{3}^{-}$out of the erythrocytes. AE1 also contributes to the $\mathrm{CO}_{2-}$ and $\mathrm{pH}$-dependent oxygen-carrying capacity of hemoglobin- 
also known as the Bohr effect. About 25\% of total protein in erythrocytes is eAE1 (Fairbanks et al., 1971).

AE1 is also densely expressed in the basolateral membrane of $\alpha$-intercalated cells in distal nephron segments of the kidney (Alper et al., 1989). Kidney AE1 (kAE1) lacks the N-terminal 65-amino acid residues found in eAE1 (Figure 1). In the distal nephron, kAE1 promotes basolateral uptake of intracellular $\mathrm{HCO}_{3}^{-}$that is formed from apical $\mathrm{H}^{+}$secretion for subsequent urinary excretion. AE1 mRNA has also been detected in the heart (Kudrycki et al., 1990; Richards et al., 1999) and colon (Kudrycki et al., 1990) where the protein's role is less defined.

AE2 is found in the basolateral membrane of most epithelia. AE2 is functionally similar to AE1 in having a $1: 1 \mathrm{Cl}^{-}: \mathrm{HCO}_{3}^{-}$ exchange stoichiometry. There are three AE2 variants (Figure 2) that derive from alternate promoters, and they are designated by the letters $a, b$, and c (e.g., AE2a). AE2b and AE2c each have two additional variants designated 1 (AE2b1 and AE2c1) and 2 (AE2b2 and AE2c2) that arise from either overlapping promoter sequences (for $\mathrm{AE} 2 \mathrm{~b}$ ) or splicing (for $\mathrm{AE} 2 \mathrm{c}$ ). The $\mathrm{N}$ termini of the AE2 variants are much longer than the corresponding $\mathrm{N}$ termini of either AE1 variant. AE2a is ubiquitous among tissue types. $\mathrm{AE} 2 \mathrm{~b}$ is less ubiquitous and densely expressed in stomach tissue.
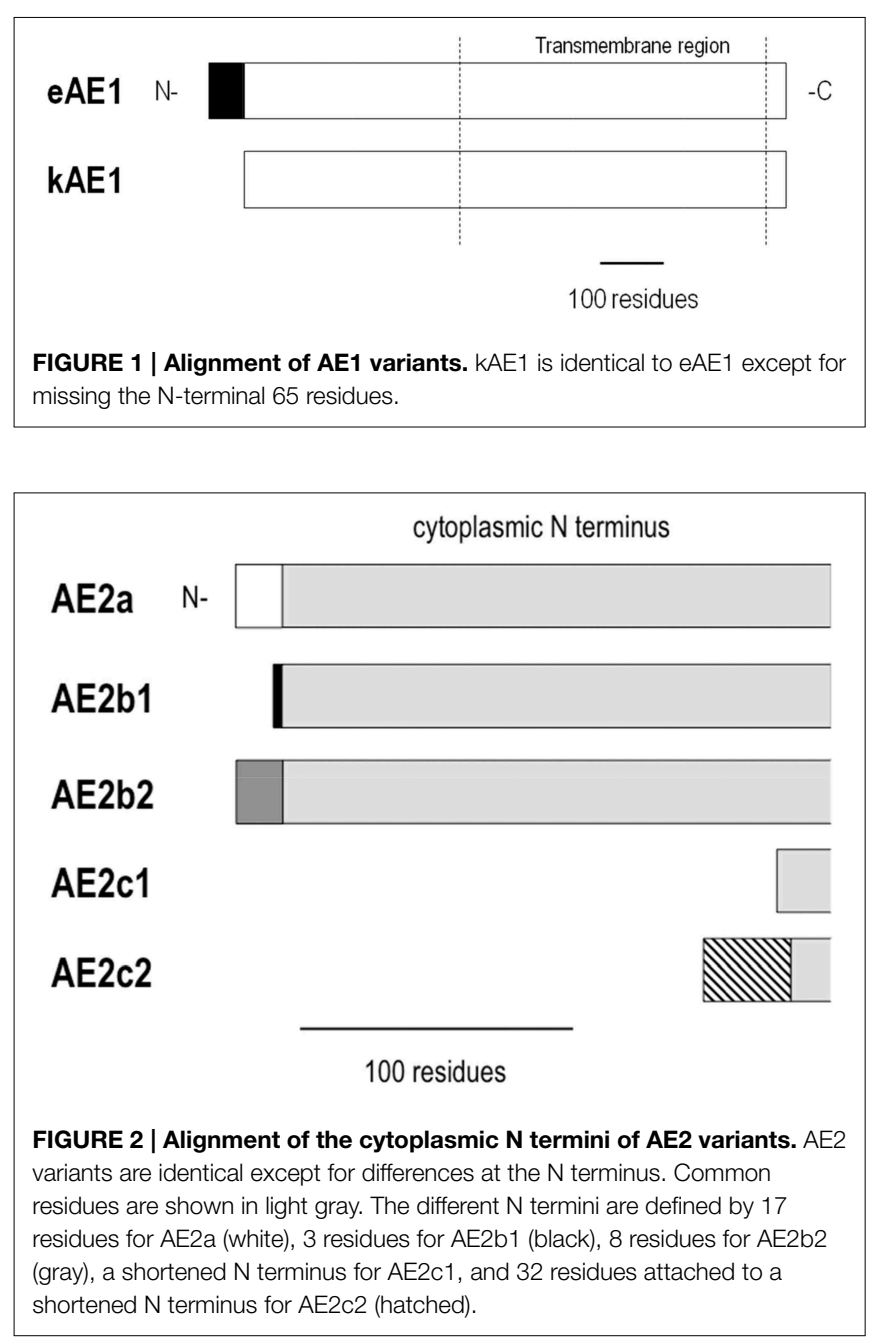

AE2c is expressed exclusively in stomach tissue (Wang et al., 1996).

\section{Carbonic Anhydrase}

Carbonic anhydrase (CA) is an enzyme that catalyzes the net reversible reaction $\mathrm{CO}_{2}+\mathrm{H}_{2} \mathrm{O} \leftrightarrow \mathrm{H}_{2} \mathrm{CO}_{3}$, which is in rapid equilibrium with $\mathrm{HCO}_{3}^{-}$and $\mathrm{H}^{+}$. In the presence of $\mathrm{CA}$, the rate of the hydration reaction is nearly limited by diffusion. It is clear that CA activity promotes the formation or removal of $\mathrm{HCO}_{3}^{-}$that can influence BT activity. Endogenous CA isozyme II (CAII) in HEK293 cells appears to keep AE1 maximally active based on the observations that AE1 is inhibited by either applying the CA inhibitor acetazolamide or co-expressing a dominant negative CAII, but unaffected by co-expressing wildtype CAII (Sterling et al., 2001). Sowah and Casey (2011) presented evidence that active CAII fused to the $\mathrm{C}$ terminus of AE1 stimulates AE1-mediated changes in intracellular $\mathrm{pH}$ and chloride. In this study, the dominant-negative effect of a catalytically inactive CAII implicates a physical interaction between CAII and AE1. In exploring the functional interplay between CA in AE activity, investigators have provided evidence that CAII directly interacts with AE1 to form a "metabolon" by binding to the short 33-residue $\mathrm{C}$ terminus of AE1. It has been proposed that the proximity of CAII to AE1 provides localized generation or removal of $\mathrm{HCO}_{3}^{-}$to adjust $\mathrm{AE} 1$ activity. However, binding of CAII to AE1, and its functional implications remain controversial.

There is experimental evidence that both supports and refutes a physical interaction between $\mathrm{CA}$ and AE. Results consistent with a direct interaction come from solid phase binding assays with purified CAII and a C-terminal 33-residue peptide of AE1 conjugated to GST (GST-AE1), which can be detected by ELISA using an antibody to GST (Vince and Reithmeier, 1998). GST-AE1 (10 nM) interacted with immobilized CAII under physiological conditions of $\mathrm{pH}$ and ionic strength, and the binding rate increased by either raising the GSTAE1 concentration or lowering the $\mathrm{pH}$ and ionic strength. Furthermore, an antibody to the C-terminal residues inhibited the CAII-AE1 interaction. The binding site within AE1 for immobilized CAII was identified as residues 887DADD in a mutagenesis study and based on the ability of mutant untagged AE1 constructs to compete with wild-type GST-AE1 for binding (Vince and Reithmeier, 2000). Results from additional early studies also provide support for a direct CA-AE interaction. For example, in the aforementioned CAII-AE1 study with HEK293 cells, mutating the putative CA binding domain of AE1 reduced the exchanger activity (Sterling et al., 2001).

However, results from more recent studies do not support CAII binding directly to the $\mathrm{C}$ terminus of AE1. In a binding assay similar to that described above, Piermarini et al. (2007) replicated the finding that the GST-tagged C terminus of AE1 bound to immobilized CAII to a greater extent than the GST alone, however untagged AE1 did not bind. When reciprocal experiments were performed with either immobilized AE1, GST-AE1, or GST, soluble CAII displayed undetectable binding to untagged AE1, and bound to the fusion protein with approximately half the apparent affinity as to GST 
alone. Using surface plasma resonance to investigate potential transient interactions, the authors found that the CAII inhibitor acetazolamide (positive control), but not the untagged AE1 Cterminal construct interacted with immobilized CAII (Piermarini et al., 2007). The group concluded that GST-tagged C-terminal AE1 constructs and GST itself in the mobile phase bind to immobile CAII, while non-tagged constructs do not. The authors did not rule out the existence of an AE1-CAII metabolon, but concluded that it would be independent of the putative Cterminal domain of AE1. Similar results were obtained with CAII and the putative CAII-binding domains at the $\mathrm{C}$ termini of NBCe1 and NDCBE (Piermarini et al., 2007). These results sound a word of caution when assessing results from binding assays using labeled protein.

More recent evidence against direct binding of CAII to AE1 was obtained by FRET analysis using tsA201 cells cotransfected with the optimized FRET pair CAII-CyPet and YPet-AE1 (Al-Samir et al., 2013). Using single-channel confocal microscopy to examine the cross-sectional distribution of each fluorophore-conjugated protein, the authors found that AE1 was predominantly expressed in the plasma membrane, while CAII was homogenously expressed throughout the cell. CAIICyPet and YPet-AE1 did not interact based on FRET analysis. In positive-control experiments, FRET was observed in cells transfected with the following two constructs: AE1 conjugated to either YPet at the $\mathrm{N}$ terminus or CyPet at the $\mathrm{C}$ terminus.

\section{Glycophorin A}

Glycophorin A (GPA) is a single membrane passing sialoglycoprotein of 131 residues that is enriched in erythrocytes (for a review, see Chasis and Mohandas, 1992). GPA contains antigenic determinants of the MNS blood group. Co-expressing AE1 with GPA - but not glycophorin B or C - enhanced both AE1 expression and AE1-mediated ${ }^{36} \mathrm{Cl}^{-}$uptake in Xenopus laevis oocytes (Groves and Tanner, 1992, 1994). Different regions of GPA are responsible for increasing AE1 expression and function. For example, mutating extracellular residues 61-70 of GPA decreased the activity of AE1, while mutating the cytoplasmic domain of GPA inhibited trafficking of the protein to the cell surface (Young and Tanner, 2003). Erythrocytes that lack eAE1 also lack GPA. These data are consistent with AE1 functioning as a chaperone-like protein and recruiting GPA to the plasma membrane, where it then stimulates the transporter (Hassoun et al., 1998). There appears to be a mutual dependency between AE1 and GPA for proper expression. As suggested by Groves and Tanner (1992), GPA influences AE1 biosynthesis, and may synchronize increased plasma membrane expression of active AE1 with maturation of the erythrocyte.

GPA stimulation of AE1 may account for the observation that some AE1 mutations cause recessive distal renal tubular acidosis and hemolytic anemia, but retain normal anion transport in erythrocytes. One such AE1 mutant, G701D, displays reduced expression and function $\left({ }^{36} \mathrm{Cl}^{-}\right.$uptake) compared to wild-type AE1 when expressed in oocytes (Tanphaichitr et al., 1998; Young and Tanner, 2003). However, co-expressing GPA increased both expression and function of the G701D mutant to levels seen with wild-type AE1. These oocyte data provide a mechanistic explanation for the normal anion transport function of G701D
AE1 in erythrocytes containing GPA, but not in the distal kidney where $\alpha$-intercalated cells lack GPA.

\section{Glyceraldehyde-3-phosphate Dehydrogenase}

Many glycolytic enzymes, including glyceraldehyde-3-phosphate dehydrogenase (GAPDH), aldolase, phosphofructokinase, lactate dehydrogenase, and pyruvate kinase bind to either AE1 itself or AE1-associated proteins (Chu and Low, 2006; Campanella et al., 2008). With the exception of GAPDH, the influence of glycolytic enzymes on AE1 activity is poorly understood. GAPDH catalyzes the conversion of glyceraldehyde-3-phosphate to D-glycerate1,3-bisphosphate in the sixth step of glycolysis. GAPDH stimulated eAE1 expression in the basolateral membrane of MDCKI cells (Su et al., 2011). The C terminus of AE1 is responsible for the interaction. $\mathrm{kAE} 1$, but not a variant truncated at the $\mathrm{C}$ terminus by 11 residues, bound $\mathrm{GAPDH}$ in a yeast 2-hybrid screen ( $\mathrm{Su}$ et al., 2011). GAPDH also interacts with eAE1 from rat erythrocytes and kAE1 from rat liver based on coimmunoprecipitation results (Su et al., 2011). GAPDH also binds to AE2 through a common anion exchanger C-terminal motif DEYxE (Su et al., 2011), although the functional consequences of this GADPH-AE2 interaction have not been demonstrated.

\section{Adaptor Protein-1}

Adaptor Protein-1 (AP-1) facilitates the exit of cargo proteins from the trans-Golgi by promoting the binding of clathrin. An siRNA-mediated decrease in the $\mu 1 \mathrm{~A}$ subunit of AP-1 inhibited the surface expression of co-transfected kAE1 in HEK293T cells (Sawasdee et al., 2010). In a similar study on MDCK1 cells, $\mu 1 \mathrm{~A}$ siRNA caused intracellular retention of human kAE1 (Almomani et al., 2012). Basolateral targeting of kAE1 was rescued by co-transfecting an siRNA-resistant $\mu 1 \mathrm{~A}$ subunit. In the same MDCK1 study, similar siRNA results were obtained for the $\mu 1 \mathrm{~B}$ subunit of AP-1. The AP-1 interaction with kAE1 requires the transporter's $\mathrm{C}$ terminus. The $\mathrm{C}$-terminal 36 residues of kAE1 (bait) bound to the $\mu 1 \mathrm{~A}$ subunit of AP-1 in a yeast two-hybrid screen of a human kidney cDNA library (Sawasdee et al., 2010). AP-1 binding was confirmed and assigned to the kAE1 motif 904YDEV based on results from mutagenesis.

\section{Src-family Kinases}

Src-family kinases are tyrosine kinases encoded by the Src gene, and their phosphorylation of AE1 stimulates rapid internalization of the transporter (Yannoukakos et al., 1991; Williamson et al., 2008). In kAE1-expressing MDCK1 cells, kAE1 residues Y359 and Y904 were not phosphorylated under basal conditions (Williamson et al., 2008). However, treating the cells with the phosphatase inhibitor pervanadate caused phosphorylation of these two residues, and subsequent internalization of AE1. A variety of Src-family kinase inhibitors blocked this pervanadate effect. Curiously, the kAE1 point mutants Y359A and Y904A - both of which cannot be phosphorylated- displayed intracellular retention. These data are consistent with both the type of residue at position 359 and 904 and its phosphorylation state (by Src-family kinases) modulating plasma membrane expression of AE1. The authors proposed that a stimulus (e.g., a change in $\mathrm{pH}_{\mathrm{i}}$ ) that shifts the balance of tyrosine kinase and phosphatase activities could 
alter kAE1 activity. This mechanism might be physiologically important, and responsible for basolateral AE1 stimulation in $\alpha$-intercalated kidney cells that promotes transepithelial acid secretion during metabolic acidosis, and inhibition that reduces acid secretion during metabolic alkalosis.

\section{Protein 4.2}

Protein 4.2 is an ATP-binding membrane protein found in erythrocytes. Protein 4.2 maintains stability and integrity of the erythrocyte membrane based on the observation that patients with protein 4.2 deficiencies present with spherocytosis and hemolytic anemia (Sung et al., 1992). In co-expression studies, protein 4.2 stimulated eAE1-mediated ${ }^{36} \mathrm{Cl}^{-}$uptake, and the proteins co-immunoprecipitated (Toye et al., 2005). Three mutant protein $4.2 \mathrm{~s}$ that cause hereditary spherocytosis were also assayed for binding and function. Two of these proteins, the Tozeur and Komatsu protein 4.2 mutants, did not stimulate or bind eAE1, and also failed to traffic to the membrane (Toye et al., 2005). The other mutant (Nippon) did traffic to the membrane and had similar stimulatory effects on eAE1 as wild-type protein 4.2- a finding consistent with proper trafficking of protein 4.2 being required for full AE1 stimulation. The mechanism by which protein 4.2 stimulates eAE1 at the membrane is not clear, and may involve either an increase in AE1 expression or transporter activity.

\section{Protein 4.1}

The $\mathrm{N}$ paralog of protein 4.1 is associated with the cytoskeleton in erythrocytes and provides structural rigidity to the membrane by stabilizing the spectrin-actin interaction (Baines et al., 2014). It is well established that the cytoplasmic domain of the erythrocyte
AE1 protein binds protein 4.1 (Pasternack et al., 1985; Jöns and Drenckhahn, 1992). Protein 4.1 binds dimeric AE1 in forming a protein 4.1-GPC junctional complex, which also includes the proteins adducin, p55, and Rh (van den Akker et al., 2010). However, protein 4.1 regulation of AE1 is less established. Protein 4.1 may contribute to the confirmation of $\mathrm{AE} 1$, or regulate transport activity/expression in association with other regulatory proteins, e.g., through crosslinking (Baines et al., 2014). It is worth noting that the $\mathrm{B}$ paralog of protein 4.1 has been reported to bind $\mathrm{NBCe} 1$ in the kidney proximal tubule in association with p55 (Terada et al., 2007). Thus, protein 4.1 regulation of BTs may not be restricted to AE1. Protein 4.1 may also stimulate the activity of NCBTs by altering their conformation or attracting other regulatory proteins.

\section{Nephrin}

Nephrin is a protein necessary for proper glomerular filtration, and is required for kAE1 expression in glomeruli. Native kAE1 expression is inhibited in human glomeruli with the nephrin mutation NPHS1(FinMaj) (Wu et al., 2010). Furthermore, transfecting wild-type nephrin into podocytes from these glomeruli restored kAE1 expression. According to results from a yeast two-hybrid screen of a human kidney cDNA library, a C-terminal region of AE1 (877-911) binds nephrina finding confirmed in immunoprecipitation studies with HEK293 cells heterologously expressing AE1 mutants. Mutual expression is further evident from the observation that nephrin expression is reduced in the AE1-knockout mouse (Wu et al., 2010).

Regulators of cloned AE1 variants are shown in Figure 3.

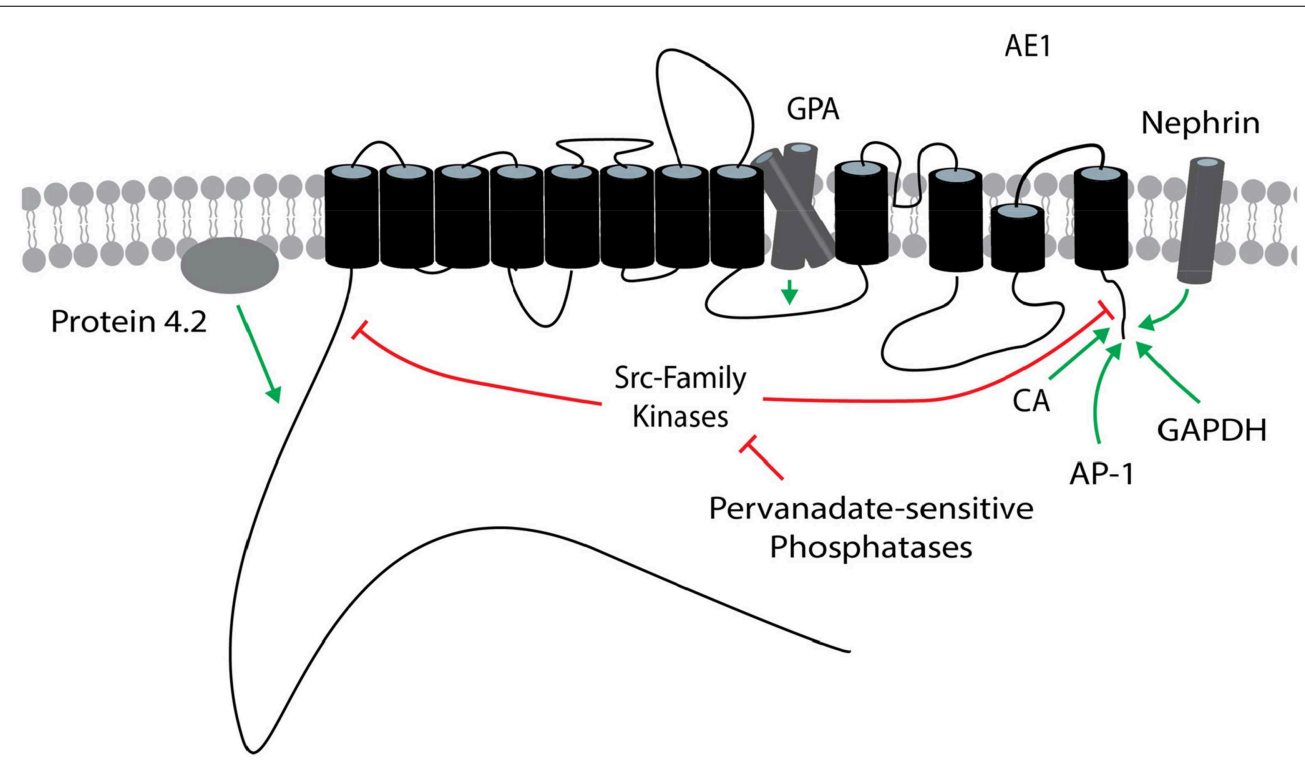

FIGURE 3 | Regulators of AE1. The general position(s) of known or potential target site(s) within AE1 for each regulator is/are shown. Stimulatory effects are depicted by green arrows and inhibitory effects are depicted by red lines. These effects involve changes in transport function and/or plasma membrane expression, and may be variant dependent. The target site of protein 4.2 is unknown within the cytosolic $N$ terminus of AE1. The AE1 topology is based on that presented in Cordat and Reithmeier (2014). AE1, anion exchanger 1; AP-1, adapter protein-1; CA, carbonic anhydrase; GAPDH, glyceraldehyde-3-phosphate dehydrogenase; GPA, glycophorin A. 


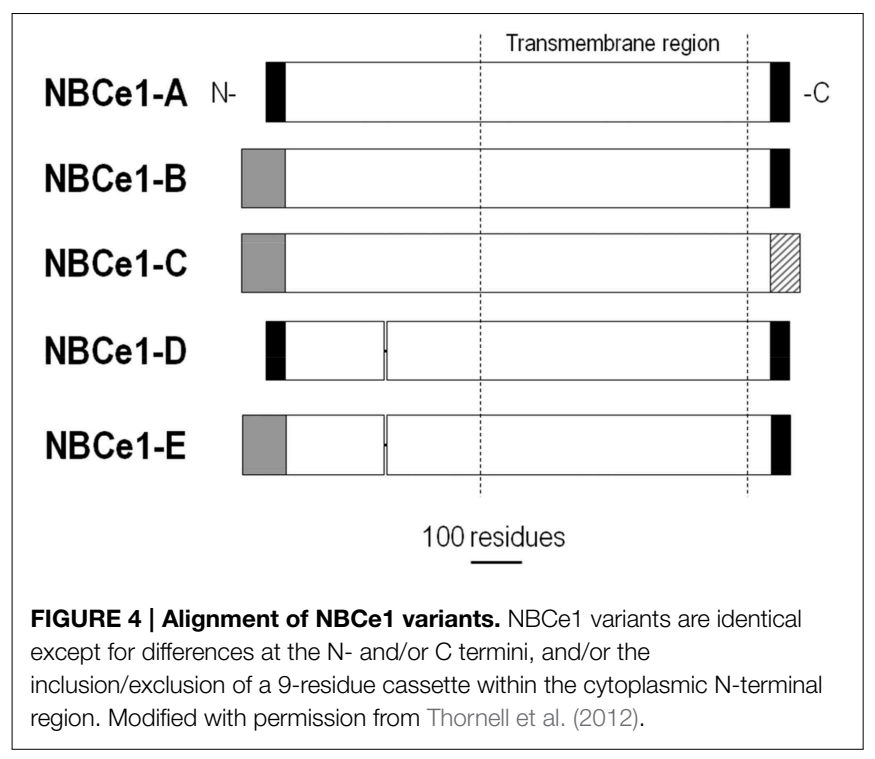

\section{NBCe1 (SIc4a4)}

NBCe1 variants are found in many tissues where they are responsible for $\mathrm{pH}_{\mathrm{i}}$ regulation, as well as solute absorption and secretion by epithelia. As depicted in Figure 4, NBCe1-A contains a different $\mathrm{N}$ terminus than $\mathrm{NBCe} 1-\mathrm{B} / \mathrm{C}$, and NBCe1-C contains a different $\mathrm{C}$ terminus than NBCe1-A/B. NBCe1-D is identical to NBCe1-A, except for the absence of the amino-acid sequence RMFSNPDNG found within the common N-terminal region of $\mathrm{NBCe} 1-\mathrm{A} / \mathrm{B} / \mathrm{C}$ (i.e., after the variable $\mathrm{N}$-terminal region and before the transmembrane region in Figure 4). NBCe1-E is identical to NBCe1-B, but lacks the aforementioned RMFSNPDNG amino acid sequence. The function of NBCe1$\mathrm{D}$ and $-\mathrm{E}$ remains to be examined. NBCe1-A/B/C - and presumably the $\mathrm{D}$ and $\mathrm{E}$ variants - have either a $1: 2$ or $1: 3$ $\mathrm{Na}^{+}: \mathrm{HCO}_{3}^{-}$stoichiometry.

NBCe1-A plays a major role in $\mathrm{HCO}_{3}^{-}$reabsorption in the proximal tubule of the kidney. Filtered $\mathrm{HCO}_{3}^{-}$and secreted $\mathrm{H}^{+}$into the tubule lumen are converted to $\mathrm{CO}_{2}$ and $\mathrm{H}_{2} \mathrm{O}$ in a net reaction catalyzed by luminal CAIV activity. Generated $\mathrm{CO}_{2}$ in the tubule lumen diffuses into the epithelial cell where intracellular CAII converts the $\mathrm{CO}_{2}$ plus $\mathrm{H}_{2} \mathrm{O}$ back into $\mathrm{H}^{+}$ and $\mathrm{HCO}_{3}^{-}$. The $\mathrm{H}^{+}$is secreted into the tubule lumen for subsequent reactions with more $\mathrm{HCO}_{3}^{-}$. The intracellular $\mathrm{HCO}_{3}^{-}$ is reabsorbed into the blood via a basolateral NBCe1-A (Boron and Boulpaep, 1983) with a 1:3 stoichiometry (Soleimani et al., 1987).

NBCe1-B is also located in the basolateral membrane of epithelial cells, and has been shown to contribute to $\mathrm{HCO}_{3}^{-}$ secretion in many tissues, including the pancreas (Muallem and Loessberg, 1990) and airway (Garnett et al., 2011; Shan et al., 2012). In these epithelia, the inward transport of net-negative charge and $\mathrm{HCO}_{3}^{-}$helps establish the electrical gradient and $\mathrm{HCO}_{3}^{-}$chemical gradient that drive $\mathrm{HCO}_{3}^{-}$secretion across the apical membrane. The electrical gradient can also drive the apical secretion of additional anions, particularly $\mathrm{Cl}^{-}$. In addition to transporting solutes across epithelia, NBCe1-B/C contribute to general $\mathrm{pH}_{\mathrm{i}}$ shifts, which are especially significant in the nervous system where corresponding changes in $\mathrm{pH}_{\mathrm{o}}$ can modulate neuronal firing (Chesler, 2003). The transporter in glial cells such as astrocytes plays a particularly important role in coupling $\mathrm{pH}$ changes with voltage changes. More specifically, following neuronal firing, elevated extracellular $\mathrm{K}^{+}$ depolarizes the membrane of astrocytes, thereby stimulating the electrogenic NBCe1. This NBCe1-mediated $\mathrm{HCO}_{3}^{-}$transport alkalinizes the astrocyte, as well as acidifies the extracellular space that tends to dampen further neuronal activity. Neurons also express NCBTs, particularly electroneutral ones such as NBCn1 and NDCBE (Majumdar and Bevensee, 2010). Thus, NBCe1 is likely the dominant NCBT responsible for the $\mathrm{pH}_{\mathrm{i}}$ physiology of astrocytes and activity-evoked $\mathrm{pH}_{\mathrm{o}}$ changes, whereas neuronal electroneutral NCBTs contribute to the $\mathrm{pH}_{\mathrm{i}}$ physiology of neurons independent of voltage changes and therefore make a smaller contribution to activity-evoked $\mathrm{pH}_{\mathrm{o}}$ changes. However, this profile is likely an oversimplification based on the more-recent evidence that neurons can also exhibit functional electrogenic NBC activity (Majumdar, 2009; Majumdar and Bevensee, 2010; Svichar et al., 2011).

\section{Carbonic Anhydrase}

Carbonic anhydrase (CA) catalyzes the slow reaction $\mathrm{H}^{+}+$ $\mathrm{HCO}_{3}^{-} \leftrightarrow \mathrm{CO}_{2}+\mathrm{H}_{2} \mathrm{O}$. While monitoring NBCe1 shortcircuit current, Gross et al. (2002) found that the CA inhibitor acetazolamide reduced the activity of NBCe1-A operating with a $1: 3$, but not a $1: 2 \mathrm{Na}^{+}: \mathrm{HCO}_{3}^{-}$stoichiometry. The authors proposed that phosphorylation of $\$ 982$, which is responsible for the stoichiometry change to 1:2 (Gross et al., 2002), eliminates CA binding to NBCe1-A. Interestingly, S982 lies in close proximity to a predicted CA binding site 986DNND, which is similar to the CAII-binding sequence DADD of AE1 (Vince and Reithmeier, 1998).

The Kurtz group proposed that 958LDDV was another CAIIbinding site in NBCe1-A (Pushkin et al., 2004). Pushkin et al. (2004) used pull-down assays and measured acetazolamidesensitive currents for $\mathrm{NBCe} 1$ constructs expressed in a mouse proximal tubule cell line, where heterologously expressed NBCe1-A displays a $1: 3 \mathrm{Na}^{+}: \mathrm{HCO}_{3}^{-}$stoichiometry (Gross et al., $2001 \mathrm{a}, \mathrm{b})$. The authors found that the degree of acetazolamide inhibition of NBCe1 correlated with the degree of CAII/NBCe1A binding. NBCe1-A mutants that bound CAII weakly were more insensitive to acetazolamide than wild-type NBCe1-A, which displayed the strongest CAII binding. In the proposed model, 958LDDV and 986DNND are part of a single binding site. Indeed, according to results from isothermal titration calorimetry, human kidney NBCe1-A has 1 high-affinity binding site for CAII with a binding constant of $160 \mathrm{nM}$ (in proteinfree PBS buffer) (Gross et al., 2002). CAII activity also appears to stimulate other NBCe1 variants. Expressing a catalytically reduced CAII mutant in HEK293 cells reduced the activity of co-expressed NBCe1-B (Alvarez et al., 2003).

Similar to CAII regulation of AE1, direct binding of CAII to NBCe1 remains controversial. In the aforementioned CAII/NBCe1 studies, reducing CAII activity or mutating the 
putative CAII binding site on NBCe1 inhibited NBCe1 activity. However, injecting Xenopus oocytes with CAII protein failed to stimulate NBCe1-A (Lu et al., 2006). CAII was functional in these experiments based on the observation that $\mathrm{pH}_{\mathrm{i}}$ recoveries from $\mathrm{CO}_{2}$-induced acidifications were faster and were inhibited by the membrane-permeant CAII inhibitor ethoxzolamide. In additional experiments, the authors found that CAII fused to a GFP-tagged NBCe1-A construct (eGFP-NBCe1-A) displayed no enhanced NBC activity over the control eGFP-NBCe1-A construct. Furthermore, no co-localization of NBCe1-A and endogenous CAII was evident compared to that seen with CAII synthetically conjugated to NBCe1-A. Discrepancies in these findings from those of the Pushkin et al. study may reflect different cell type-dependent NBCe1 stoichiometries. NBCe1A has a $1: 2 \mathrm{Na}^{+}: \mathrm{HCO}_{3}^{-}$when expressed in Xenopus oocytes (Heyer et al., 1999; Sciortino and Romero, 1999; McAlear et al., 2006), but a $1: 3 \mathrm{Na}^{+}: \mathrm{HCO}_{3}^{-}$stoichiometry when expressed in the proximal tubule cell line used in the Pushkin et al. study (Gross et al., 2001a).

In a more recent Xenopus oocyte study, Schueler et al. (2011) found that CAI-CAIII all stimulated NBCe1-A-mediated $\mathrm{pH}_{\mathrm{i}}$ recoveries and currents when oocytes were held at $-40 \mathrm{mV}$. CAI lacks the putative $\mathrm{N}$-terminal residues for NBCe1-A binding (3HH...9KH...15H...17H), and CAIII has alternative residues 3E and 9S within this domain (Schueler et al., 2011). Thus, these experiments support the contention that an interaction is not necessarily required for CA stimulation of NBCe1.

CAIV, an outer plasma membrane glycosylphosphatidylinositol-anchored CA, also stimulated NBCe1-B co-expressed in HEK293 cells (Alvarez et al., 2003). The authors also showed by pull-down assays and immunodetection that CAIV - obtained by lysing CAIVexpressing cells- bound to GST-conjugated NBCe1-B. CAIV binding to and functional stimulation of NBCe1-B was dependent on residue G767 found in the fourth extracellular loop of NBCe1-B that is conserved in CAIV-binding AE1, but not in AE3 (Alvarez et al., 2003). CAIV is expected to stimulate all NBCe1 variants, which have this conserved glycine at position 767 .

\section{Autoregulation}

When expressed in Xenopus oocytes, NBCe1-A has $\sim$ four-fold greater activity than NBCe1-B or -C (McAlear et al., 2006). NBCe1-A differs from NBCe1-B and $-\mathrm{C}$ at its $\mathrm{N}$ terminus (Figure 4), and removing this different $\mathrm{N}$ terminus reduces NBCe1-A activity by approximately half. Thus, there appears to be an autostimulatory domain (ASD) within this $\mathrm{N}$ terminus of the A variant that stimulates activity. The ASD is also expected to contribute to the activity of NBCe1-D, which has the same N terminus (Figure 4). Currently, there are no known regulators of the ASD. This ASD may contribute to the efficient reabsorption of $\mathrm{HCO}_{3}^{-}$in the kidney by promoting high-velocity NBCe1-Amediated transport of $\mathrm{HCO}_{3}^{-}$across the basolateral membrane in the proximal tubule.

Autoregulation has also been demonstrated for the $\mathrm{N}$ terminus of NBCe1-B and -C. Truncating the $\mathrm{N}$ terminus of NBCe1-C stimulated the transporter 2.7-fold (McAlear et al.,
2006). Furthermore, the activity of this truncated variant was similar to that of the corresponding NBCe1-A truncation (i.e., they had similar whole oocyte currents). Therefore, the $\mathrm{N}$ terminus of NBCe1-B or -C appears to contain an autoinhibitory domain (AID). As described below, this AID is at least partially regulated by other binding proteins, especially inositol 1,4,5trisphosphate (IP3) receptor binding protein released with IP3 (IRBIT). NBCe1-E is also predicted to have an AID because it contains the same $\mathrm{N}$ terminus as NBCe1-B and $-\mathrm{C}$ (Figure 4).

The specific $\mathrm{C}$ terminus of NBCe1-C may also influence regulation by the AID based on the following two observations with NBCe1 stimulators soon to be discussed. First, coexpressing IRBIT in oocytes stimulated co-expressed NBCe1-C to a greater extent (i.e., more relief of the AID) than NBCe1-B (Thornell et al., 2010). Second, removing the AID-containing $\mathrm{N}$ terminus of NBCe1-C - but not NBCe1-B - resulted in a small but significant $\mathrm{IP}_{3}$-induced stimulation that required $\mathrm{ER}$-store $\mathrm{Ca}^{2+}$ (Thornell et al., 2012). Based on these observations, the $\mathrm{C}$ terminus of NBCe1-C either contributes to a joint N-terminal/Cterminal AID or contains a separate AID.

\section{IRBIT-WNK/SPAK}

IRBIT is a ubiquitous second messenger protein that binds to the $\mathrm{IP}_{3}$ receptor and competes with intracellular $\mathrm{IP}_{3}$ (Ando et al., 2003). IRBIT released from the $\mathrm{IP}_{3}$ receptor into the cytosol regulates many proteins, including channels and transporters (Ando et al., 2014). When heterologously expressed in Xenopus oocytes, IRBIT stimulated human NBCe1-B, but not NBCe1A (Shirakabe et al., 2006). In similar oocyte co-expression experiments, IRBIT also stimulated rat NBCe1-B and -C, but not mutants with N-terminal truncations (Thornell et al., 2010). In co-immunoprecipitation studies, IRBIT bound to NBCe1B, but not NBCe1-A (Shirakabe et al., 2006) - data consistent with IRBIT binding to the different $\mathrm{N}$ terminus of the $\mathrm{B}$ and C variants. Mutating the phosphorylated residue S68 or S71 in IRBIT's PEST domain to an Ala still enabled IRBIT to bind to the $\mathrm{IP}_{3}$ receptor (Ando et al., 2009). However, these mutants failed to bind to and stimulate NBCe1-B (Shirakabe et al., 2006), and failed to stimulate NBCe1-C (Thornell et al., 2012). Thus, there are different regions of IRBIT responsible for $\mathrm{IP}_{3}$ receptor binding and NBCe1 stimulation.

Results from pull-down assays comparing the binding of IRBIT to different serial truncations of NBCe1-B indicated that amino acid regions 1-18 and 37-62 were necessary for IRBIT binding (Shirakabe et al., 2006). In expression studies with HeLa cells, Hong et al. (2013) demonstrated that a stretch of arginines (42-44) within the positively charged region 37-65 of NBCe1-B is required for IRBIT binding and stimulation. Double, triple, but not single, arginine to alanine replacements greatly reduced IRBIT binding, while the triple replacement eliminated IRBIT stimulation of transport. In addition to these basic arginine residues, T49 is also required for IRBIT regulation. In a separate study, NBCe1-B amino acid residues between 4 and 16 were also required for IRBIT stimulation (Lee et al., 2012c). These functional data support Shirakabe et al.'s prediction that the IRBIT binding and stimulatory determinants of NBCe1-B 
involve multiple motifs within a complex tertiary structure rather than a single motif (Shirakabe et al., 2006).

Seki et al. (2008) proposed that IRBIT stimulates NBCe1$B$ by removing the AID inhibition. If true, then expressing IRBIT and removing the AID should stimulate NBCel activity to the same extent. IRBIT contains a binding domain for protein phosphatase-1 (PP-1) (Devogelaere et al., 2007). As such, it is difficult to activate IRBIT fully because it is normally inhibited by the ubiquitous phosphatase PP-1. To activate IRBIT maximally, the Boron group mutated IRBIT's PP-1 binding site to create a super-IRBIT (Lee et al., 2012c). The activity of NBCe1-B co-expressed with super-IRBIT exceeded the activity of the $\mathrm{N}$ terminal truncation of NBCe1-B lacking the putative N-terminal AID (Lee et al., 2012c). The authors concluded that IRBIT did not stimulate NBCe1-B through relief of the AID exclusively. The AID's tertiary structure may include other parts of the transporter, such as a putative C-terminal AID as mentioned above.

IRBIT and its binding partner PP-1 are linked to other regulatory molecules (Figure 5). PP-1 antagonizes the WNK (with-no-lysine kinase)/SPAK (STE20/SPS1-related proline/alanine-rich kinase) pathway (Yang et al., 2011). Human WNK/SPAK mutations cause hypertension- a finding that implicates this pathway as a regulator of epithelial electrolyte transport (Wilson et al., 2001). Indeed, WNK/SPAK regulates many epithelial ion channels and transporters including the $\mathrm{Na} / \mathrm{K} / 2 \mathrm{Cl}$ cotransporter (Anselmo et al., 2006), the epithelial sodium channel (Heise et al., 2010), the cystic fibrosis transmembrane conductance regulator (Yang et al., 2007), the renal outer medullary $\mathrm{K}^{+}$channel (He et al., 2007), and NBCe1-B and -C (Yang et al., 2009).

In HeLa cells, the WNK/SPAK pathway also inhibits NBCe1B (Yang et al., 2011; Hong et al., 2013). Transfecting either WNK or kinase-dead WNK mutants inhibited NBCe1-Bconsistent with WNK acting as a scaffold, not a kinase, for another NBCe1 regulator such as SPAK (Yang et al., 2011). Cotransfecting kinase-dead SPAK with WNK blocked the WNKmediated inhibition of NBCe1. The phosphorylation of S65 by SPAK was required for the SPAK-mediated decrease in NBCe1-B surface expression (Hong et al., 2013). These data are consistent with WNK recruiting SPAK to phosphorylate NBCe1-B and to reduce $\mathrm{NBCe1-B}$ surface expression. This WNK/SPAK-mediated

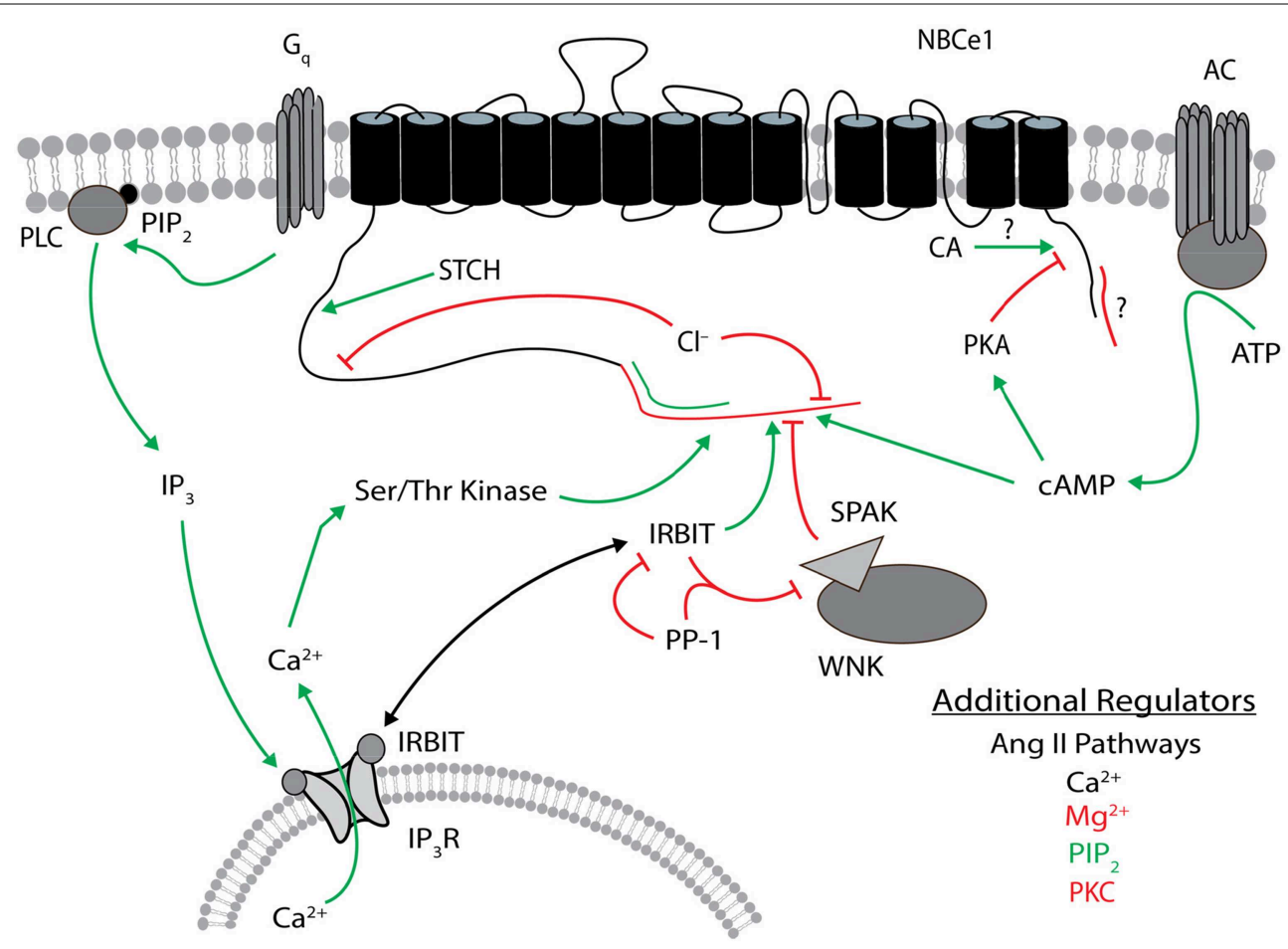

FIGURE 5 | Regulators of NBCe1. The general position(s) of known or approximate target site(s) within NBCe1 for each regulator is/are shown. Stimulatory effects are depicted by green arrows and inhibitory effects are depicted by red lines. The $\mathrm{N}$ terminus of NBCe1-B and $-\mathrm{C}$ that contains the autoinhibitory domain is shown in red, and the different $N$ terminus in $-A$ that contains the autostimulatory domain is shown in green. The different $\mathrm{C}$ terminus of NBCe1-C (vs. -A/B) that contains a possible autoinhibitory domain is shown in red. Direct binding of carbonic anhydrase to the $\mathrm{C}$ terminus remains controversial. The target site of STCH is unknown within the cytosolic N-terminal residues $96-440$ of NBCe1-B. Ser/Thr kinase involves a site within the different $\mathrm{N}$ terminus of the $\mathrm{B} / \mathrm{C}$ variants. Additional regulators listed are not as well characterized, especially regarding their target sites on NBCe1. These additional regulators in black type can be either stimulatory or inhibitory. Regulatory effects involve changes in transport function and/or plasma membrane expression, and may be variant dependent. The NBCe1 topology is based on that presented in Parker and Boron (2013). CA, carbonic anhydrase; $\mathrm{IP}_{3}$, inositol 1,4,5-trisphosphate; $I_{3} R, I_{3}$ receptor; $I R B I T, I P_{3} R$ binding protein released with $I_{3} ; P_{2}$, phosphatidylinositol 4,5-bisphosphate; PKA, protein kinase A, PKC, protein kinase C; PLC, phospholipase C; PP-1, protein phosphatase 1; SPAK, STE20/SPS1-related proline/alanine-rich kinase; STCH, Hsp70-like stress 70 protein chaperone; WNK, with-no-lysine kinase. 
NBCe1-B inhibition was antagonized by IRBIT recruitment of the phosphatase PP-1 (Yang et al., 2011; Hong et al., 2013). The phosphorylation of NBCe1-B residue T49 is also required for both the IRBIT and WNK/SPAK pathways, and the T49A substitution eliminated regulation by both proteins (Hong et al., 2013). The WNK/SPAK and IRBIT/PP-1 pathways have also been reported to converge with the regulator $\mathrm{PIP}_{2}$, which also appears to require the positively charged $\mathrm{N}$ terminal region $37-$ 65 (Hong et al., 2013). However, the $\mathrm{IP}_{3} / \mathrm{Ca}^{2+}$ pathway may be involved. In summary, whereas IRBIT stimulates NBCe1-B and -C, WNK/SPAK antagonizes these NBCel variants (see review by Park et al., 2012). In addition to the direct IRBIT stimulation of NBCe1, IRBIT indirectly disinhibits NBCe1 from WNK/SPAK by recruitment of PP-1. This signaling complex likely regulates fluid and electrolyte transport in the pancreatic duct (Yang et al., 2009, 2011; Park et al., 2012). For example, purinergic hormones and cholecystokinin that stimulate pancreatic $\mathrm{HCO}_{3}^{-}$ secretion through an increase in intracellular $\mathrm{IP}_{3}$ are expected to displace IRBIT from the $\mathrm{IP}_{3}$ receptor. This cytosolic IRBIT now inhibits WNK/SPAK and increases basolateral NBCe1 activity (responsible for $\mathrm{HCO}_{3}^{-}$uptake from the interstitium), as well as apical CFTR and Slc26a6 activities (both responsible for $\mathrm{HCO}_{3}^{-}$ transport into the duct). We recommend Lee et al. (2012a) for a more detailed description of pancreatic $\mathrm{HCO}_{3}^{-}$secretion.

IRBIT's effect on NBCe1-B surface expression depends on the expression system. Co-expressing IRBIT and NBCe1-B in Xenopus oocytes did not change surface NBCe1 protein assayed by confocal imaging (Shirakabe et al., 2006), single-oocyte chemiluminescence (Thornell et al., 2010), or biotinylation and subsequent immune-detection (Lee et al., 2012c). However, IRBIT increased NBCe1-B surface expression in HeLa cells (Yang et al., 2011). The basis of this discrepancy may be a less active WNK/SPAK pathway in oocytes than HeLa cells. If so, then the majority of NBCe1-B would already be expressed on the oocyte membrane, and only an expression-independent increase in transporter current is observed. Consistent with this explanation, co-expressing NBCe1-B and IRBIT in HeLa cells suppressed WNK/SPAK-mediated NBCel internalization and stimulated NBCe1-B by a WNK/SPAK-independent mechanism (Hong et al., 2013) - most likely by the expression-independent mechanism characterized for IRBIT and NBCe1 in oocytes.

\section{$\mathrm{PIP}_{\mathbf{2}}$}

Phosphatidylinositol 4,5-bisphosphate $\left(\mathrm{PIP}_{2}\right)$ is a minor membrane phospholipid involved in many cellular processes including the regulation of channels and transporters (Di Paolo and De Camilli, 2006; Balla, 2013). The rat-kidney NBCe1-A current displays rundown in a macropatch of Xenopus oocyte membrane that can be inhibited and reversed by directly applying a fast membrane incorporating short-chain $\mathrm{PIP}_{2}(\mathrm{Wu}$ et al., 2009). In addition, NBCe1-A current rundown is inhibited by vanadate and $\mathrm{Mg}^{2+}$-free solutions. These data are consistent with an initial, endogenous $\mathrm{PIP}_{2}$-dependent transporter current that rapidly decays due to $\mathrm{Mg}^{2+}$-sensitive phosphatase activity that decreases $\mathrm{PIP}_{2}$.

These findings in isolated membrane patches have been extended to the whole oocyte. Injecting exogenous $\mathrm{PIP}_{2}$ into an oocyte to raise $\mathrm{PIP}_{2}$ is not straightforward because the injected $\mathrm{PIP}_{2}$ is rapidly hydrolyzed to $\mathrm{IP}_{3}$ by phospholipase C (PLC) (Thornell et al., 2012). Nonetheless, blocking PIP $_{2}$ hydrolysis by pretreating the oocyte with the PLC inhibitor U73122 resulted in a modest $\mathrm{PIP}_{2}$ injection-induced stimulation of $\mathrm{NBCe} 1-$ A, -B, and -C (Thornell et al., 2012). Importantly, NBCe1-A was not stimulated by the $\mathrm{PIP}_{2}$ injection in the absence of U73122. Therefore, the $\mathrm{PIP}_{2}$-induced stimulation observed in the presence of U73122 was not the result of incomplete PLC inhibition. The modest $\mathrm{PIP}_{2}$-induced stimulation of NBCe1 may indicate that $\mathrm{PIP}_{2}$ is near it maximal effective concentration in oocytes. As such, decreasing $\mathrm{PIP}_{2}$ may be a better assay for exploring $\mathrm{PIP}_{2}$ regulation of $\mathrm{NBCe} 1$.

We have recently found that a decrease in membrane $\mathrm{PIP}_{2}$ itself - independent of $\mathrm{IP}_{3}$ - inhibits NBCe1-B and -C expressed in Xenopus oocytes (Thornell and Bevensee, 2015). Degrading $\mathrm{PIP}_{2}$ was achieved by co-expressing NBCe1 with a voltagesensitive phosphatase (VSP) that dephosphorylates $\mathrm{PI}(4,5) \mathrm{P}_{2}$ to PI(4)P. Activating VSP by sufficient depolarization inhibited NBCe1-B and -C. Importantly, depolarizing oocytes to voltages that do not sufficiently activate the VSP, or using a phosphatasedead mutant (C366S VSP) did not inhibit NBCe1-mediated currents or $\mathrm{pH}_{\mathrm{i}}$ recoveries from an acid load. Furthermore, in simultaneous voltage-clamp and confocal imaging experiments with a $\mathrm{PIP}_{2}$-sensitive fluorescent probe, VSP-elicited changes in NBCel current mirrored $\mathrm{PIP}_{2}$ changes in the plasma membrane.

Where might $\mathrm{PIP}_{2}$ bind to NBCe1? Based on crystallography data of the Kir2.2-PIP 2 and the GIRK2-PIP 2 interactions (Hansen et al., 2011; Whorton and MacKinnon, 2011), these $\mathrm{K}^{+}$channels have a non-specific phospholipid domain within the transmembrane (TM) region, as well as a polycationic $\mathrm{PIP}_{2}$ binding domain in the cytosol near one TM region. NBCe1 variants contain similar $\mathrm{PIP}_{2}$-binding motifs, including KDKKKKEDEKKKKKKK in the cytosolic C-terminus, RKHRH in the cytosolic $\mathrm{N}$ terminus, and RKEHKLKK before TM8. The region before TM8 is of particular interest because TM8 is involved in ion translocation (McAlear and Bevensee, 2006). An additional $\mathrm{PIP}_{2}$-binding motif, RRRRRHKRK is found in the $\mathrm{N}$ terminus of NBCe1-B and -C. Recently, Hong et al. (2013) reported that a trimer of arginines (42-44) within this region is required for $\mathrm{PIP}_{2}$ stimulation of NBCe1-B. However, this region may play a role in $\mathrm{IP}_{3} / \mathrm{Ca}^{2+}$ regulation instead. This region is unlikely to be the sole $\mathrm{PIP}_{2}$-binding region because it is absent in the $\mathrm{PIP}_{2}$-sensitive NBCe1-A.

\section{$\mathrm{IP}_{\mathbf{3}}$ and $\mathrm{Ca}^{2+}$}

Injecting $\mathrm{PIP}_{2}$ into whole Xenopus oocytes expressing NBCe1-B or $-\mathrm{C}$, but not NBCe1-A, stimulated the NBC current (Thornell et al., 2012). The majority of this stimulation was mediated by $\mathrm{PIP}_{2}$ hydrolysis to $\mathrm{IP}_{3}$, required an intracellular $\mathrm{Ca}^{2+}$ store, and involved a staurosporine-sensitive Ser/Thr kinase (Thornell et al., 2012). Raising intracellular $\mathrm{Ca}^{2+}$ (e.g., by applying ionomycin and activating membrane $\mathrm{Ca}^{2+}$ channels and $\mathrm{G}_{\mathrm{q}}$-coupled receptors) also stimulated the $\mathrm{B}$ and $\mathrm{C}$ variants. This mode of stimulation also required the distinct $\mathrm{N}$ terminus of the $\mathrm{B} / \mathrm{C}$ variant. Thus, kinase-mediated phosphorylation of NBCe1 or an NBCe1 regulator may relieve the $\mathrm{N}$-terminal AID. As previously 
reported, such a kinase pathway may also be responsible for observed ATP stimulation of NBCe1-A in the macropatch (Heyer et al., 1999). Activating endogenous $\mathrm{G}_{\mathrm{q}}$-coupled receptors in Xenopus oocytes by applying lysophosphatidic acid (LPA) stimulated the activity of heterologously expressed NBCe1-C. However, LPA stimulated the activity of heterologously expressed NBCe1-B by an increase in expression in physiological conditions (Thornell et al., 2012). In recent experiments, LPA stimulated NHE3 expression through the Ser/Thr kinase p90 ribosomal S6 kinase (RSK) (No et al., 2015). These similarities raise the possibility that RSK may be involved in LPA-induced stimulation of at least NBCe1-B.

NBCe1-A expressed in whole Xenopus oocytes was minimally stimulated by $\mathrm{PIP}_{2}$ injection, and unaffected by raising intracellular $\mathrm{Ca}^{2+}$, e.g., by activating store-operated $\mathrm{Ca}^{2+}$ channels (Thornell et al., 2012). However, in a separate study, raising bath $\mathrm{Ca}^{2+}$ from 100 to $500 \mathrm{nM}$ stimulated the slope conductance of rat NBCe1-A in a fraction of inside-out oocyte macropatches. Based on I-V data, the stimulation involved an increase in the stoichiometry from $1: 2$ to $1: 3 \mathrm{Na}^{+}: \mathrm{HCO}_{3}^{-}$(MüllerBerger et al., 2001). Thus, $\mathrm{Ca}^{2+}$ regulation of $\mathrm{NBCe} 1-\mathrm{A}$ is clearly different in the whole cell vs. at least a fraction of isolated membrane patches.

\section{$\mathrm{PIP}_{2}$ vs. $\mathrm{IP}_{3} / \mathrm{Ca}^{2+}$}

The aforementioned evidence that $\mathrm{PIP}_{2}$ can stimulate all three NBCe1 variants directly, or NBCe1-B and $-\mathrm{C}$ indirectly through its hydrolysis and subsequent $\mathrm{IP}_{3} / \mathrm{Ca}^{2+}$, raises the question of which is the dominant pathway (Thornell and Bevensee, 2015). This dual mode of regulation is similar to that reported for the KCNQ-mediated M current in superior cervical ganglion cells (Zhang et al., 2003; Gamper et al., 2004; Suh and Hille, 2005; Winks et al., 2005; Zaika et al., 2011). We believe the inhibitory effect of $\mathrm{PIP}_{2}$ hydrolysis will dominate when $\mathrm{G}_{\mathrm{q}}$ receptors are activated away from a Ca ${ }^{2+}$ source. Thus, there is no $\mathrm{Ca}^{2+}$ release that can activate lipid kinases that normally replenish the $\mathrm{PIP}_{2}$. In contrast, the stimulatory effect of $\mathrm{PIP}_{2}$ hydrolysis to $\mathrm{IP}_{3} / \mathrm{Ca}^{2+}$ will dominate when the receptors are activated near a $\mathrm{Ca}^{2+}$ source. Alternatively, the $\mathrm{IP}_{3} / \mathrm{Ca}^{2+}$ pathway may predominate under physiological conditions with adequate energy levels. However, the $\mathrm{PIP}_{2}$ pathway would play the dominant role with energy (ATP) depletion, for example, associated with anoxia or hypoxia. An associated decrease in $\mathrm{PIP}_{2}$ may inhibit transporters such as NBCe1 in a protective way to minimize large intracellular $\mathrm{Na}^{+}$and $\mathrm{Ca}^{2+}$ loads and/or to conserve remaining energy. Such inhibition may counteract the deleterious effect of NBCe1 stimulation in the ischemic heart as described above. Finally, as suggested by Hilgemann et al. (2001), the PIP $_{2}$ requirement for NBCel function may keep the transporters necessarily inactive during maturation and trafficking through organelles prior to expression at the plasma membrane.

\section{Angiotensin II, PKC, and $\mathrm{Ca}^{2+}$}

It is well established that endogenous NBCe1-A is stimulated by low concentrations $\left(10^{-11}-10^{-9} \mathrm{M}\right)$ of angiotensin II (Ang II) and inhibited by high concentrations $\left(10^{-9}-10^{-6} \mathrm{M}\right)$ of Ang II (Geibel et al., 1990; Eiam-Ong et al., 1993; Coppola and Frömter,
1994; Ruiz et al., 1995; Robey et al., 2002; Zheng et al., 2003). Ang II-mediated bimodal regulation has been reported for NBCe1A heterologously expressed in Xenopus oocytes co-expressing the Ang II receptor AT $_{1 \mathrm{~A}}$ (Perry et al., 2006, 2007). Low concentrations of Ang II increased the depolarization-induced NBCe1 current through a $\mathrm{Ca}^{2+}$-dependent mechanism that could be inhibited by BAPTA (Perry et al., 2006). However, high concentrations of Ang II inhibited this NBCe1 current through a pathway involving $\mathrm{Ca}^{2+}$-insensitive protein kinase $\mathrm{C}, \mathrm{PKC} \varepsilon$ that reduced expression at the plasma membrane (Perry et al., 2006, 2007). Interestingly, both a PKC $\varepsilon$ inhibitor and the $\mathrm{Ca}^{2+}$ chelator BAPTA reduced the high Ang II-mediated NBCel inhibition, perhaps through separate pathways. Furthermore, the Ang IIinduced inhibition was irreversible after applying calmodulin inhibitors or monensin - a finding consistent with high Ang II inhibiting NBCe1-A trafficking to the plasma membrane in oocytes. Thus, results from heterologous expression studies have provided mechanistic insight into the concentration-dependent, Ang II-mediated bimodal regulation of endogenous NBCe1 in kidney.

\section{Acetylcholine}

Acetylcholine (ACh) is a neurotransmitter that activates either ionotropic or metabotropic receptors. Metabotropic ACh receptor activation promotes anion secretion in many epithelial cell types such as acinar cells in the pancreas (Steward and Ishiguro, 2009; Lee et al., 2012a). Curiously though, applying carbachol lowered membrane expression of both transiently expressed NBCe1-A and NBCe1-B in acinar ParC5 cells (Perry et al., 2009). Furthermore, contradictory to secretion observed in native tissue, pretreating NBCe1-B-expressing HEK293 cells with carbachol did not alter NBCe1-B activity (Bachmann et al., 2008). The paradoxical findings may be the result of NBCe1 overexpression or cell-type specific cAMP-mediated pathways, which can merge with metabotropic ACh signaling and jointly regulate anion secretion (e.g., in the pancreas, Lee et al., 2012a).

\section{CAMP}

cAMP is a second messenger formed by adenylate cyclase (AC)mediated catalysis of ATP. It is well established that a hormoneinduced increase in cAMP decreases renal tubular $\mathrm{HCO}_{3}^{-}$ absorption and increases pancreatic duct $\mathrm{HCO}_{3}^{-}$secretion (McKinney and Myers, 1980; Liu and Cogan, 1989; Ishiguro et al., 1996a,b; Kunimi et al., 2000). However, less is known about the molecular mechanisms by which cAMP alters the activity of $\mathrm{NBCe} 1-$ the dominant $\mathrm{Na}^{+}$-coupled $\mathrm{HCO}_{3}^{-}$transporter in these tissues.

There is evidence that cAMP can contribute to a change in transport stoichiometry of NBCe1 from $1: 3$ to $1: 2 \mathrm{Na}^{+}: \mathrm{HCO}_{3}^{-}$ through protein kinase A (PKA)-mediated phosphorylation of either S982 of the A variant or the homologous S1026 of the B variant (Gross et al., 2001a,b, 2003). Furthermore, the base stoichiometry and response to cAMP of NBCe1-A and $B$ have been reported to be cell-type dependent (Gross et al., 2003). In the kidney proximal tubule, this stoichiometry change would account for observed inhibition of net $\mathrm{HCO}_{3}^{-}$efflux by cAMP-elevating dopamine (Kunimi et al., 2000) and parathyroid 
hormone (McKinney and Myers, 1980). However, it is now clear that the regulation of NBCe1 stoichiometry is complex and not fully understood. For example, additional factors can influence NBCe1 stoichiometry, including intracellular $\mathrm{Ca}^{2+}$ (see above, Müller-Berger et al., 2001), other residues such as T485 (A variant), which is part of putative TM3 (Zhu et al., 2013), and even assay-dependent measurements (Zhu et al., 2013).

cAMP can also stimulate NBCe1-B activity, as indicated by an increase in slope conductance, without an apparent change in stoichiometry (Gross et al., 2003). cAMP stimulation of NBCe1$B$ required residue T49 located in the PKA phosphorylation site of the different N-terminus, although did not require a change in its phosphorylation state. Curiously, this $\mathrm{Thr}$ at position 49 in human NBCe1-B is not conserved across species, and is an Ala in rat NBCe1-B. This mode of cAMP stimulation was also observed for NBCe1-B expressed in $\mathrm{mPT}$ cells as indicated by an increase in slope conductance (in addition to the reversal potential shift described above). Secretin-induced $\mathrm{HCO}_{3}^{-}$secretion by the pancreatic duct may be due, at least in part, to CAMP stimulation of NBCe1-B in the basolateral membrane (Ishiguro et al., 1996a,b).

\section{Magnesium}

Free cytosolic $\mathrm{Mg}^{2+}$ remains fairly constant in a variety of physiological conditions - ranging from 0.5 to $0.7 \mathrm{mM}$ (Romani, 2007). Yamaguchi and Ishikawa (2008) expressed bovine NBCe1-B in HEK293 and NIH3T3 cells, and monitored whole-cell $\mathrm{Na}^{+}$-dependent $\mathrm{HCO}_{3}^{-}$currents by patch clamping while varying the $\mathrm{Mg}^{2+}$ concentration in the pipette solution. For HEK293 cells, $\mathrm{Mg}^{2+}$ inhibited $\mathrm{Na}^{+}$dependent $\mathrm{HCO}_{3}^{-}$currents with $\mathrm{K}_{\mathrm{i}}$ values that appeared voltage-independent (e.g., $\sim 15 \mu \mathrm{M}$ at $-20 \mathrm{mV}, \sim 11 \mu \mathrm{M}$ at $+20 \mathrm{mV}$, and $\sim 11 \mu \mathrm{M}$ at $+40 \mathrm{mV}$ ). A similar $\mathrm{Mg}^{2+}$-induced NBCe1-B inhibition was observed for NIH3T3 cells. The AID of NBCe1-B was involved because an N-terminal truncation of $\mathrm{NBCe} 1-\mathrm{B}$ raised the $\mathrm{K}_{\mathrm{i}}$ for $\mathrm{Mg}^{2+}$ to $300 \mu \mathrm{M}$.

Endogenous NBCe1-B in bovine parotid acinar cells was also inhibited by $\mathrm{Mg}^{2+}$ with $~$ eight-fold higher $\mathrm{K}_{\mathrm{i}}$ values (Yamaguchi and Ishikawa, 2008). The rightward shift in $K_{i}$ from the previous expression systems was likely due to cell-type specific regulation. For example, IRBIT co-transfection increased the $\mathrm{K}_{\mathrm{i}}$ for $\mathrm{Mg}^{2+}$ induced inhibition of NBCe1-B stably transfected into HEK293 cells from $560 \mathrm{nM}$ to $11 \mu \mathrm{M}$ (Yamaguchi and Ishikawa, 2012). However, it is not clear why the $\mathrm{K}_{\mathrm{i}}$ for $\mathrm{Mg}^{2+}$-induced NBCe1$\mathrm{B}$ inhibition in this study was lower than in the previous study (Yamaguchi and Ishikawa, 2008).

$\mathrm{Mg}^{2+}$ may inhibit NBCe1-B by disrupting $\mathrm{PIP}_{2}$ stimulation of the transporter. More specifically, the cationic $\mathrm{Mg}^{2+}$ may screen the negative charges of $\mathrm{PIP}_{2}$ (Suh and Hille, 2007), which we have recently shown to stimulate NBCe1 (Thornell et al., 2012; Thornell and Bevensee, 2015). Consistent with this mechanism, other polyvalent cations such as neomycin (Yamaguchi and Ishikawa, 2008) and spermine (Yamaguchi and Ishikawa, 2012) increased the $\mathrm{K}_{\mathrm{i}}$ for $\mathrm{Mg}^{2+}$-induced inhibition of NBCe1-B heterologously expressed in HEK293 and NIH3T3 cells, and endogenously expressed in bovine parotid acinar cells.
Such polycations also inhibit $\mathrm{PIP}_{2}$ stimulation of NBCe1-A (Wu et al., 2009).

Although it is well established that $\mathrm{Mg}^{2+}$ interacts and regulates ion channels and transporters, including the $\mathrm{Na}-\mathrm{K}$ and $\mathrm{Ca}^{2+}$ pumps Jorgensen et al., 2003; Lu, 2004; Romani, 2007, it is intriguing that $\mathrm{Mg}^{2+}$ also regulates $\mathrm{NBCe}$, and perhaps other NCBTs. Such regulation by divalents other than $\mathrm{Ca}^{2+}$ may play a much larger role than previously thought in acid-base handling in organs such as the kidney. As described above, cytosolic $\mathrm{Mg}^{2+}$ is relatively stable under physiological conditions. However, it can rise to over $1.0 \mathrm{mM}$ under pathological conditions such as ischemia (Murphy et al., 1989). Perhaps elevated $\mathrm{Mg}^{2+}$-induced inhibition of NBCe1 protects cells in pathological states by minimizing large intracellular $\mathrm{Na}^{+}$and $\mathrm{Ca}^{2+}$ loads- similar to that proposed above for $\mathrm{PIP}_{2}$ hydrolysis-induced inhibition of NBCe1.

\section{Chloride}

In a recent study, Shcheynikov et al. (2015) reported that intracellular $\mathrm{Cl}^{-}\left(\mathrm{Cl}_{\mathrm{i}}^{-}\right)$is a signaling ion that regulates NBCe1-A and $-\mathrm{B}$, as well as NBCe2-C expressed in $\mathrm{HeLa}$ cells. $\mathrm{High}_{\mathrm{Cl}}^{-}$ inhibits NBCe1-B and involves two GxxxP sites in the cytosolic N terminus. One is a low-affinity site active under basal conditions, whereas the other is a high-affinity site unmasked by IRBIT. Interestingly, $\mathrm{NBCe} 1-\mathrm{A}$ is insensitive to $\mathrm{Cl}_{\mathrm{i}}^{-}$in the physiological range, but does contain a single, low-affinity GxxxP site in its $\mathrm{N}$ terminus that can be unmasked by deleting residues $29-41$. NBCe2-C has a single, high-affinity GxxP in its cytosolic N terminus that is basally active. $\mathrm{Cl}_{\mathrm{i}}^{-}$regulation of $\mathrm{NBCe} 1$ appears to be cell-type dependent because IRBIT stimulates NBCe1-B expressed in oocytes, which have a high $\mathrm{Cl}_{\mathrm{i}}^{-}[\sim 35 \mathrm{mM}$ (Cooper and Fong, 2003)]. This oocyte $\mathrm{Cl}^{-}$concentration inhibits the transporter in HeLa cells under the same conditions. As the authors propose, $\mathrm{Cl}_{\mathrm{i}}^{-}$regulation of NBCe1-B could serve to couple NBCel and AE activity in a negative feedback fashion, and to promote continued $\mathrm{HCO}_{3}^{-}$secretion by epithelia in distal portions of ducts (e.g., salivary and pancreatic) where $\mathrm{Cl}_{\mathrm{i}}^{-}$ is low.

\section{Chaperone Stress 70 Protein (STCH)}

Chaperone stress 70 protein (STCH) is a ubiquitously expressed microsomal-associated protein whose cellular function is poorly understood (Bae et al., 2013). Although a member of the 70$\mathrm{kDa}$ heat-shock protein family, STCH is not activated by heat shock. STCH is expressed ubiquitously and activated by $\mathrm{Ca}^{2+}$. STCH binds to NBCe1-B based on results from a yeast 2-hybrid screen (Bae et al., 2013). Co-expressing STCH with NBCe1-B in Xenopus oocytes caused an increase in transporter current due to enhanced protein expression. The $\mathrm{N}$ terminus of $\mathrm{NBCe} 1$ was not involved because STCH co-expression also stimulated an NBCe1 truncated at its $\mathrm{N}$ terminus $(\triangle 95 \mathrm{aa})$. Furthermore, STCH and IRBIT stimulation of NBCe1-B was additive in co-expression studies, and therefore likely involve separate pathways. STCH stimulation of endogenous NBCe1-B was evident in a human submandibular gland ductile cell line, HSG (Bae et al., 2013). siRNA knockdown of STCH in HSG cells inhibited a DIDSsensitive $\mathrm{pH}_{\mathrm{i}}$ recovery from an $\mathrm{NH}_{4}^{+}$-induced acid-load, and 
decreased membrane expression of NBCe1-B. Bae et al. (2013) noted that $\mathrm{STCH}$ is down regulated in some cancers and central nervous system disorders, and the reduced stimulation of NBCe1 would promote cellular acidification.

Regulators of cloned NBCe1 variants are shown in Figure 5.

\section{NBCn1 (S/c4a7)}

$\mathrm{NBCn} 1$ variants are found in many tissue types and are regulators of $\mathrm{pH}_{\mathrm{i}}$. Additionally, $\mathrm{NBCn} 1$ is involved in coordinating epithelial absorption and secretion of solutes. There are 16 identified functional NBCn1 splice variants, NBCn1-A through -P. These splice variants are simplified by grouping variable regions into cassettes (Figure 6). Each functional variant contains 1 of 2 alternate $\mathrm{N}$-termini, and includes or excludes previously defined cassette I, II, and/or IV in the $\mathrm{N}$ terminus, and/or cassette III in the C terminus (Liu et al., 2013).

NBCn1 knockout mice and genomic data have been useful in identifying tissue-specific roles for NBCn1. The transporter plays a major role in somatosensory perception based on the finding that NBCn1 knockout mice exhibit blindness and hearing loss (Bok et al., 2003; Lopez et al., 2005). NBCn1 dysfunction is also a risk factor for hypertension in humans (Ehret et al., 2011), and this link complements the phenotype of mild hypertension in the NBCn1 knockout mouse (Boedtkjer et al., 2011).

\section{Autoregulation}

In a detailed oocyte expression study, Liu et al. (2013) discovered that each NBCn1 N-terminal region and cassette influences either membrane surface expression or activity of the transporter as measured by a $\mathrm{pH}_{\mathrm{i}}$ recovery from a cellular acid load. The MEAD $\mathrm{N}$ terminus (Figure 6; gray $\mathrm{N}$-terminus) increased $\mathrm{NBCn} 1$ surface expression, but not transporter activity, as compared

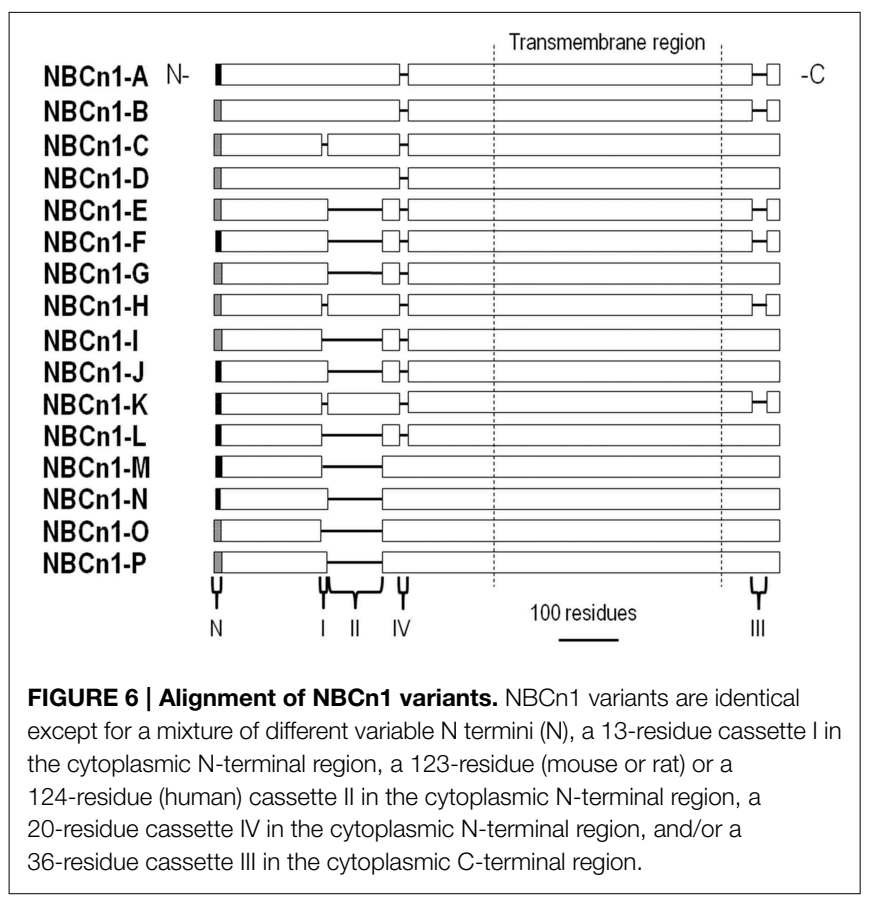

to the MERF $\mathrm{N}$ terminus. Cassettes I, II, and III regulated surface expression by interacting with multiple cassettes, thereby making it difficult to assign a specific role to any single cassette. Cassette I tended to promote surface expression, but did not stimulate transporter activity. Cassette II stimulated NBCn1 activity 3.8 -fold, and cassette III stimulated activity by 4.4 -fold. Cassette IV had the most dramatic regulatory effect- stimulating NBCn 1 activity $\sim 11$-fold, while inhibiting protein membrane abundance by $55 \%$.

\section{Carbonic Anhydrase}

CAII binding to NBCn1 is controversial as discussed above for AE1 and NBCe1. Similar to the findings with AE1, HEK293 cells co-expressing NBCn1 and a catalytically reduced CAII mutant have a slower $\mathrm{pH}_{\mathrm{i}}$ recovery from an acid load than cells expressing NBCn1 alone (Loiselle et al., 2004). However, untagged NBCn1 did not bind CAII, as described for AE1 (Piermarini et al., 2007).

\section{Calcineurin}

Calcineurin is a calcium-dependent Ser/Thr protein phosphatase found in many cell types (Rusnak and Mertz, 2000). Calcineurin interacts with cassette II of $\mathrm{NBCn} 1$ based on results from a yeast 2-hybrid screen of a human skeletal muscle cDNA library (Danielsen et al., 2013). According to further mutagenesis

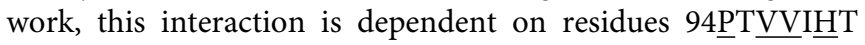
(critical amino acids are underlined) within cassette II of NBCn1. Results from surface plasmon resonance further support calcineurin binding and a subsequent conformational change of cassette II of NBCn1 (Gill et al., 2014). Regarding function, raising intracellular $\mathrm{Ca}^{2+}$ to activate calcineurin stimulated the endogenous $\mathrm{NBCn} 1-\mathrm{B}$-mediated $\mathrm{pH}_{\mathrm{i}}$ recovery from an acid load in smooth muscle cells of rat mesenteric arteries (Danielsen et al., 2013). This stimulation was inhibited by the $\mathrm{Ca}^{2+}$ chelator BAPTA and calcineurin inhibitors FK506 and cyclosporine in a non-additive fashion. Based on the modular structure of NBCn1, cassette II is found in many variants (Boron et al., 2009) and calcineurin is expected to stimulate NBCn1-A, -B, -C, -D, and $-\mathrm{H}$ (Figure 6). Calcineurin stimulation of NBCe1-B is likely physiologically important by protecting the smooth muscle cells from excessive acidosis during artery contraction (Danielsen et al., 2013).

\section{IRBIT}

As described above, IRBIT is a signaling molecule released from $\mathrm{IP}_{3}$ receptors when the cytosolic $\mathrm{IP}_{3}$ concentration rises (Ando et al., 2003). Parker et al. (2007b) demonstrated that IRBIT interacts with NBCn1-B and stimulates both the transport activity and channel-like $\mathrm{Na}^{+}$conductance of NBCn1B expressed in Xenopus oocytes. This IRBIT stimulation is not due to increased NBCn1-B expression (Mark D. Parker, personal communication). IRBIT co-expression in HeLa cells also stimulates NBCn1-A (Hong et al., 2013). Similar to that observed for NBCe1-B, this stimulation requires the homologous trimer of arginines (residues 56-58) within the cytoplasmic $\mathrm{N}$ terminus of NBCn1-A, and involves the PP-1 and WNK/SPAK pathways. Thus, IRBIT is expected to bind the other NBCn1 
variants that all have the IRBIT binding domain identified in NBCe1-B.

\section{PIP $_{2}$}

Hong et al. have presented intriguing data that $\mathrm{PIP}_{2}$ also appears to stimulate NBCn1 expressed in Xenopus oocytes, and the stimulation requires the trimer of arginines at residues 5658 (Hong et al., 2013). Thus, $\mathrm{PIP}_{2}$ regulation of BTs may not be restricted to NBCe1. However, as presented above for $\mathrm{PIP}_{2}$ studies on $\mathrm{NBCe} 1$, it is important to distinguish between the effects of $\mathrm{PIP}_{2}$ per se vs. its hydrolysis to $\mathrm{IP}_{3}$.

\section{CAMP}

cAMP is a second messenger that actives PKA, thereby phosphorylating many target proteins and activating many channels and transporters, including NBCe1 described above. Applying the PKA activators forskolin or 8-bromoadenosine stimulated NBCn1 heterologously expressed in HEK293 cells (Loiselle et al., 2004). Although this inhibition was sensitive to the PKA inhibitor H89, PKA did not alter the phosphorylation state of NBCn1. Thus, phosphorylation of an intermediate NBCn1 regulatory protein may be involved.

\section{PDZ Domain-containing Proteins}

Post-synaptic density protein 95 (PSD-95) is a scaffolding protein found in the post-synaptic density of neuronal dendrites. In addition to containing an SH3 domain and a catalytically inactive guanylate kinase domain, PSD-95 contains three PDZ domains that interact with other PDZ-containing proteins including the NMDA receptor $(\mathrm{Xu}, 2011)$. Based on co-immunoprecipitation results, PSD-95 binds to NBCn1, which contains a PDZ-binding domain (Lee et al., 2012b). Although co-expressing PSD-95 with NBCn1 did not stimulate $\mathrm{HCO}_{3}^{-}$transport, it did stimulate an NBCn1-associated channel-like conductance (Lee et al., 2012b). Syntrophin $\gamma 2$ is another cytosolic scaffolding protein that contains a PDZ domain and binds NBCn1 (Lee et al., 2014). Co-expressing syntrophin $\gamma 2$ with $\mathrm{NBCn} 1$ stimulated both $\mathrm{HCO}_{3}^{-}$transport and the NBCn1-associated channel-like conductance. Thus, PDZ domain-containing proteins can complex with NBCn1 and alter the $\mathrm{pH}$ physiology and/or electrical properties of excitable cells.

Regulators of cloned NBCn1 variants are shown in Figure 7.

\section{NDCBE (S/c4a8)}

NDCBE is present in many organs, but is most abundant in the brain where it regulates $\mathrm{pH}$ and neuronal firing (Sinning et al., 2011). There are 5 NDCBE splice variants, NDCBE-A through $\mathrm{E}$ (Figure 8). NDCBE- $\mathrm{A}$ and $-\mathrm{B}$ contain the same 16 residue $\mathrm{N}$ terminus, but vary in their $\mathrm{C}$ termini. NDCBE-C is identical to NDCBE-A, but is truncated at the $\mathrm{N}$ terminus by 54 residues. NDCBE-D is identical to NDCBE-B, but is truncated at the N terminus by 54 residues. NDCBE-E is identical to NDCBE-B, but the 16 residue $\mathrm{N}$ terminus of the $\mathrm{B}$ variant is replaced by a unique

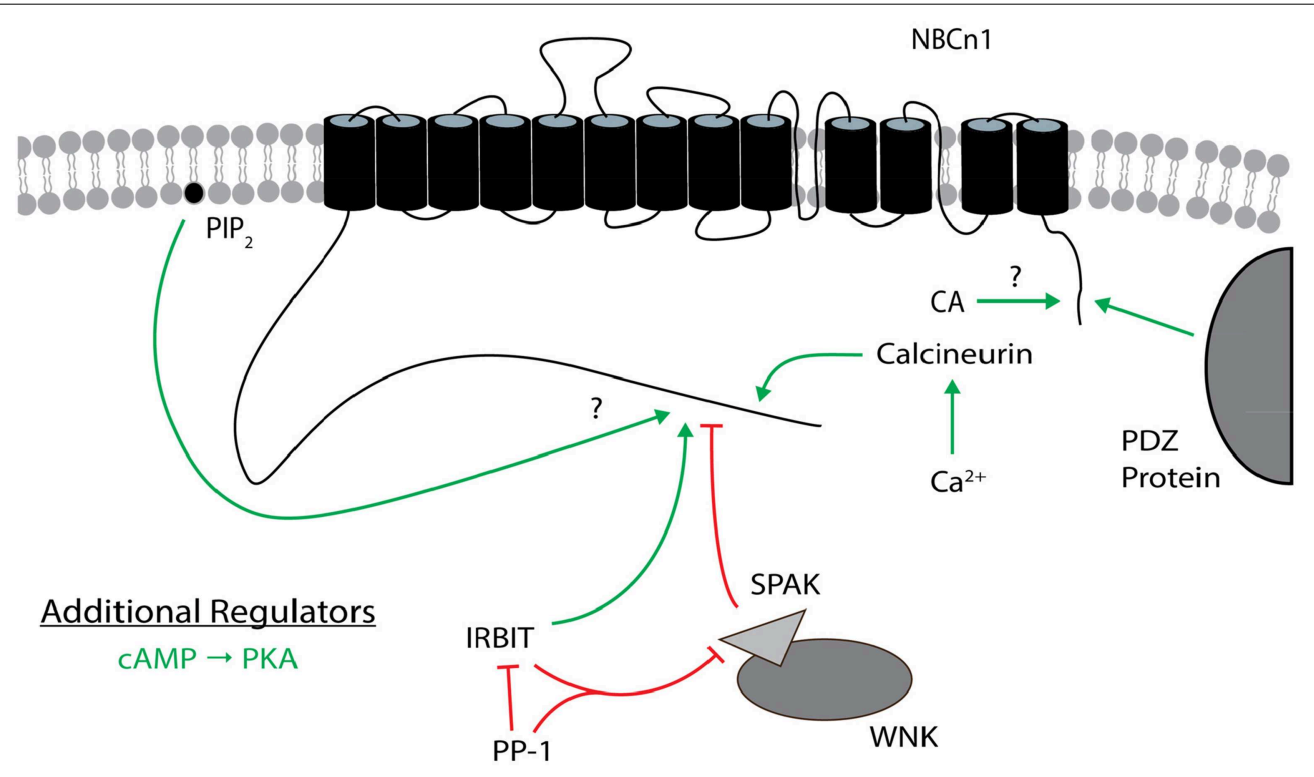

FIGURE 7 | Regulators of NBCn1. The general position(s) of known or approximate target site(s) within NBCn1 for each regulator is/are shown. Stimulatory effects are depicted by green arrows and inhibitory effects are depicted by red lines. The direct binding of CA to NBCn1 remains controversial. $\mathrm{PIP}_{2}$ may stimulate itself or following $\mathrm{PIP}_{2}$ hydrolysis. CAMP (PKA) is an additional regulator that is not as well characterized, especially regarding its target site(s) on NBCn1. These effects involve changes in transport function and/or plasma membrane expression, and may not be the same for all variants. The many splicing cassettes and their complex combinations that are either stimulatory or inhibitory are not shown. The NBCn1 topology is based on that presented in Parker and Boron (2013). CA, carbonic anhydrase; IRBIT, inositol 1,4,5-trisphosphate $\left(\mathrm{IP}_{3}\right)$ receptor binding protein released with $\mathrm{IP}_{3} ; \mathrm{PIP}_{2}$, phosphatidylinositol 4,5-bisphosphate; PKA, protein kinase A; PP-1, protein phosphatase 1; SPAK, STE20/SPS1-related proline/alanine-rich kinase; WNK, with-no-lysine kinase. 


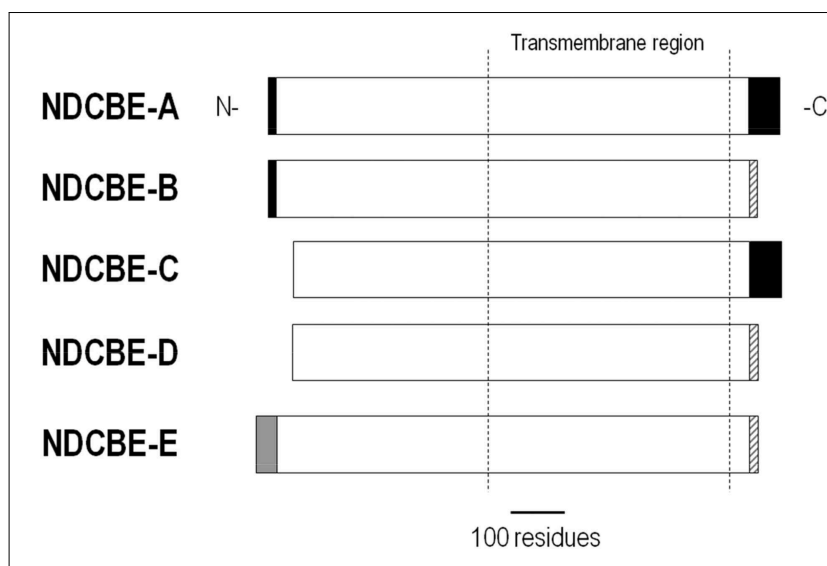

FIGURE 8 | Alignment of NDCBE variants. NDCBE variants are identical except for differences or truncations at the $\mathrm{N}$ and/or $\mathrm{C}$ termini.

43 residue $\mathrm{N}$ terminus. Of the $5 \mathrm{NDCBE}$ variants, only the $\mathrm{E}$ variant has yet to be tested for function (Parker and Boron, 2013).

\section{Autoregulation}

NDCBE-B, -D, and -E share a 17-residue C-terminal sequence (Figure 8). When expressed in Xenopus oocytes, NDCBE-B and -D have similar activities (Parker et al., 2008). Removing these 17 C-terminal residues of the $\mathrm{B}$ variant stimulated transporter activity to the level of the A variant. These findings are consistent with an AID within the different C-terminal region of NDCBE-B and $-\mathrm{D}$.

\section{IRBIT}

IRBIT, as described above, binds to and regulates other BTs including NBCe1 and NBCn1. IRBIT also binds to NDCBE$\mathrm{B}$ and stimulates the transporter current (Parker et al., 2007b). However, not all NDCBE variants are stimulated by IRBIT. Parker and Boron (2013) reported the preliminary finding that IRBIT does not stimulate NDCBE-D. This variant does contain the putative IRBIT-binding RRR sequence (residues 19-21). Thus, additional domains influence IRBIT binding to BTs, as described above for NBCe1.

\section{NBCn2 (S/c4a10)}

NBCn2 is present throughout many organs. A physiological role for $\mathrm{NBCn} 2$ has been most apparent in the brain, where $\mathrm{NBCn} 2$ regulates neuronal firing. The NBCn2 knockout mouse had impaired neuronal recovery from an acid load and a higher seizure threshold (Jacobs et al., 2008). However, disruption of the NBCn2 gene in a human patient is associated with both epilepsy and mental retardation (Gurnett et al., 2008). The role of NBCn2 outside of the nervous system remains unclear (Parker and Boron, 2013). There are four NBCn2 splice variants, NBCn2A through -D (Figure 9). NBCn2-B and -D contain a 30-residue cassette $\mathrm{A}$ within the $\mathrm{N}$ terminus. NBCn2-A and -B contain a 3residue cassette within the $\mathrm{C}$ terminus, whereas $\mathrm{NBCn} 2-\mathrm{C}$ and -D contain a 21-residue cassette within the $\mathrm{C}$ terminus that has a PDZ domain.

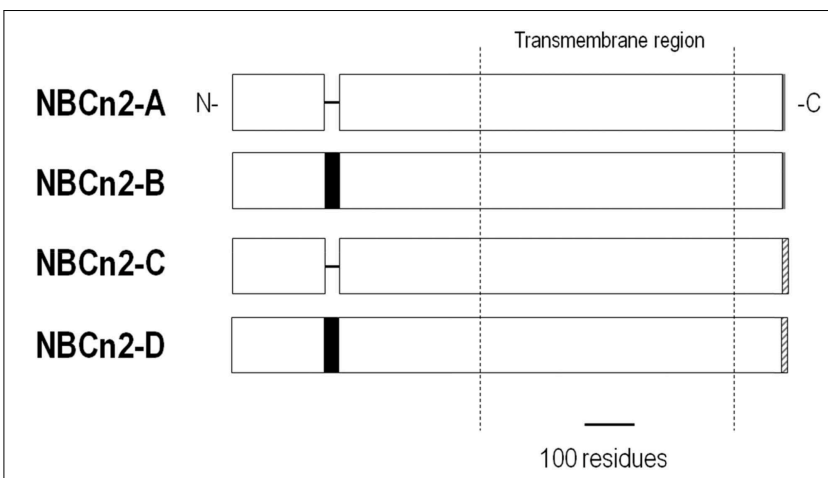

FIGURE 9 | Alignment of NBCn2 variants. NBCn2 variants are identical except for the inclusion/exclusion of a 30-residue cassette, and/or a different C terminus.

\section{Autoregulation}

Removing the N-terminal 92 residues of NBCn2-B increased transporter activity (Parker et al., 2007a). Thus, this region likely contains an AID, which is conserved among all the NBCn2 variants (Figure 9). However, the AID may be differentially regulated by other variable regions among the variants.

\section{cAMP}

cAMP inhibits NBCn2-C. Applying forskolin to 3T3 cells heterologously expressing $\mathrm{NBCn} 2-\mathrm{C}$ (reported as a variant of $\mathrm{NCBE}$ ) inhibited the $\mathrm{NBCn} 2$-mediated $\mathrm{pH}_{\mathrm{i}}$ recovery from an acid load (Lee et al., 2006). The cAMP analog 8-bromo-cAMP mimicked this inhibition, whereas the PKA inhibitory fragment 14-22 stimulated transport. Disrupting the actin cytoskeleton with cytochalasin $\mathrm{B}$ also inhibited the $\mathrm{NBCn} 2$-mediated $\mathrm{pH}_{\mathrm{i}}$ recovery. A potential protein that may link cytoskeleton structure to NBCn2 is the ezrin binding protein 50 (EBP50), which contains PDZ domains and also binds PKA. Indeed, EBP50 coimmunoprecipitated with transfected NBCn2-C in 3T3 cells (Lee et al., 2006). Because NBCn2-C and PKA can bind EBP50, the authors suggest that cAMP-induced $\mathrm{NBCn} 2-\mathrm{C}$ inhibition is an upstream regulator of EBP50 PDZ domains. Similar regulation is expected for NBCn2-D that also has a PDZ-binding domain at its $\mathrm{C}$ terminus.

\section{IRBIT}

IRBIT both binds and stimulates NBCn2 (Parker et al., 2007a,b). IRBIT stimulates $\mathrm{NBCn} 2$ without a change in membrane abundance (Mark D. Parker, personal communication).

\section{Conclusions and Future Directions}

Investigators have made considerable advances over the years in identifying and characterizing regulators of Slc4 BTs. Results from functional assays, mutagenesis, and binding studies involving immunoprecipitation and yeast 2-hybrid assays on the cloned proteins heterologously expressed in oocytes or mammalian cells have revealed a rich and diverse array of regulators and their target sites. Regulators can alter BT expression and/or function, and perhaps even transport 
stoichiometry. In addition to the classic second messengers (e.g., $\mathrm{Ca}^{2+}$, cAMP, and associated phosphorylation), there are less conventional regulators. For example, glycolytic enzymes alter the activity/expression of AE1. Autoregulatory domains influence the function of many NCBTs, and these include the $\mathrm{N}$ termini of NBCe1 and NBCn2, the C termini of NDCBE, and cassettes throughout NBCn1. Such autoregulation may underscore the functional significance of at least some NCBT variants. Some of these regulators exhibit crosstalk and modulate each other. IRBIT is a central player in the crosstalk of regulators already identified for NBCe1. While IRBIT stimulates NBCe1$\mathrm{B} / \mathrm{C}$ (at least partially) by removing the N-terminal AID, it also suppresses WNK/SPAK inhibition of the transporter. IRBIT also appears to interfere with $\mathrm{Mg}^{2+}$-induced inhibition and the $\mathrm{PIP}_{2}$ (or $\mathrm{IP}_{3} / \mathrm{Ca}^{2+}$ )-induced stimulation of $\mathrm{NBCe}$, perhaps through the AID as well. Most recently, IRBIT has been shown to promote $\mathrm{Cl}_{\mathrm{i}}^{-}$inhibition of NBCe1-B by unmasking a high-affinity GxxxP site.

The exciting advances already made will direct future efforts to understand better the physiological significance of regulators of Slc4 BTs. Appealing future areas of research involve the following:

(i) Identifying and characterizing new regulators of the cloned proteins. Other regulators and interacting proteins are expected to be identified, especially for BTs that contain PDZ-binding motifs at their $\mathrm{C}$ termini. Some regulators may therefore be variant-specific.

(ii) Addressing controversies, particularly related to the importance of CAs in BT function, and the existence of a physical BT-CA metabolon.

(iii) Determining the mechanistic basis of regulators such as glycolytic enzymes and protein 4.2 that stimulate $\mathrm{AE} 1$, and $\mathrm{PIP}_{2}$ that stimulates NBCe1. Mutagenesis data will help assign regions involved in binding. Structural information provided by biochemical techniques (such as chemical labeling and the substituted-cysteine accessibility method or SCAM), NMR, and eventual x-ray crystallography will provide insight into conformational changes that are directly responsible for altered transport function.

(iv) Elucidating the dynamic interplay and/or crosstalk among various regulators (e.g., associated with IRBIT regulation and $\mathrm{PIP}_{2}-\mathrm{IP}_{3} / \mathrm{Ca}^{2+}$ regulation). These studies are linked to (iii) above. However, a challenge will be in distinguishing regulators as competitors vs. allosteric modulators, and

\section{References}

Aiello, E. A., Petroff, M. G., Mattiazzi, A. R., and Cingolani, H. E. (1998). Evidence for an electrogenic $\mathrm{Na}^{+}-\mathrm{HCO}_{3}^{-}$symport in rat cardiac myocytes. J. Physiol. 512, 137-148. doi: 10.1111/j.1469-7793.1998.137bf.x

Almomani, E. Y., King, J. C., Netsawang, J., Yenchitsomanus, P.-T., Malasit, P., Limjindaporn, T., et al. (2012). Adaptor protein 1 complexes regulate intracellular trafficking of the kidney anion exchanger 1 in epithelial cells. Am. J. Physiol. Cell Physiol. 303, C554-C566. doi: 10.1152/ajpcell.00124.2012

Alper, S. L., Darman, R. B., Chernova, M. N., and Dahl, N. K. (2002). The AE gene family of $\mathrm{Cl} / \mathrm{HCO}_{3}^{-}$exchangers. J. Nephrol. 15(Suppl. 5), S41-S53. in determining under what conditions one regulator dominates. We expect regulatory profiles to differ among variants in some cases.

(v) Characterizing regulation of endogenous BT function in a physiological/pathophysiological setting. This direction is highlighted by the recent evidence that IRBIT and associated regulators modulate ion and fluid secretion by ductal epithelia. Additional exciting directions include determining if high $\mathrm{Mg}_{\mathrm{i}}^{2+}$ or $\mathrm{PIP}_{2}$ hydrolysis protects against cell-damaging $\mathrm{Na}_{\mathrm{i}}^{+}$and $\mathrm{Ca}_{\mathrm{i}}^{2+}$ overload by inhibiting NBCel in energy-deficient pathological conditions such as ischemia and hypoxia. For regulators of BTs that influence the electrical properties of excitable cells (e.g., heart myocytes and neurons), it will be important to assess how such regulators impact overall tissue excitability and function. Results from in-vivo and in-vitro physiological studies on specific BT knockout (KO) animals will elucidate the specific transporters or variants responsible. However, targeting a specific BT that represents a splice variant will be genetically challenging in $\mathrm{KO}$ studies. Conditional $\mathrm{KO}$ animals will be valuable in assessing the role of specific transporters/variants without confounding compensatory expression profiles.

Undoubtedly, the field will continue to evolve with new discoveries that will highlight the complexity of $\mathrm{pH}_{\mathrm{i}}$ physiology. Multiple regulatory mechanisms for a single Slc4 protein and/or the presence of many different Slc4 proteins impart a cell with an intricate signaling network to orchestrate $\mathrm{pH}_{\mathrm{i}}$ regulation under different conditions and stimuli.

\section{Author Contributions}

The manuscript was written and edited by IMT and MOB.

\section{Acknowledgments}

This work was supported by an award from the American Heart Association (Southeast Affiliate, 14GRNT20480021 to MOB), and an award from the NIH/NIGMS (T32GM008111 to IMT). We thank Dr. Mark D. Parker (Department of Physiology and Biophysics and the Department of Opthalmology, State University of New York [SUNY] at Buffalo) for reading a preliminary version of this manuscript, and providing helpful comments and suggestions. of intercalated cells in rat kidney collecting duct defined by antibodies against erythroid band 3 and renal vacuolar $\mathrm{H}^{+}$-ATPase. Proc. Natl. Acad. Sci. U.S.A. 86, 5429-5433. doi: 10.1073/pnas.86.14.5429

Al-Samir, S., Papadopoulos, S., Scheibe, R. J., Meißner, J. D., Cartron, J.P., Sly, W. S., et al. (2013). Activity and distribution of intracellular carbonic anhydrase II and their effects on the transport activity of anion exchanger AE1/SLC4A1. J. Physiol. 591, 4963-4982. doi: 10.1113/jphysiol.2013. 251181

Alvarez, B. V., Loiselle, F. B., Supuran, C. T., Schwartz, G. J., and Casey, J. R. (2003). Direct extracellular Interaction between carbonic anhydrase IV and the human 
NBC1 sodium/bicarbonate co-transporter. Biochemistry 42, 12321-12329. doi: 10.1021/bi0353124

Ando, H., Kawaai, K., and Mikoshiba, K. (2014). IRBIT: a regulator of ion channels and ion transporters. Biochim. Biophys. Acta 1843, 2195-2204. doi: 10.1016/j.bbamcr.2014.01.031

Ando, H., Mizutani, A., Matsu-ura, T., and Mikoshiba, K. (2003). IRBIT, a novel inositol 1,4,5-trisphosphate $\left(\mathrm{IP}_{3}\right)$ receptor-binding protein, is released from the $\mathrm{IP}_{3}$ receptor upon $\mathrm{IP}_{3}$ binding to the receptor. J. Biol. Chem. 278, 10602-10612. doi: 10.1074/jbc.M210119200

Ando, H., Mizutani, A., and Mikoshiba, K. (2009). An IRBIT homologue lacks binding activity to inositol 1,4,5-trisphosphate receptor due to the unique N-terminal appendage. J. Neurochem. 109, 539-550. doi: 10.1111/j.14714159.2009.05979.x

Anselmo, A. N., Earnest, S., Chen, W., Juang, Y. C., Kim, S. C., Zhao, Y., et al. (2006). WNK1 and OSR1 regulate the $\mathrm{Na}^{+}, \mathrm{K}^{+}, 2 \mathrm{Cl}^{-}$cotransporter in HeLa cells. Proc. Natl. Acad. Sci. U.S.A. 103, 10883-10888. doi: 10.1073/pnas.0604607103

Bachmann, O., Franke, K., Yu, H., Riederer, B., Li, H. C., Soleimani, M., et al. (2008). cAMP-dependent and cholinergic regulation of the electrogenic intestinal/pancreatic $\mathrm{Na}^{+} / \mathrm{HCO}_{3}^{-}$cotransporter $\mathrm{pNBC} 1$ in human embryonic kidney (HEK293) cells. BMC Cell Biol. 9:70. doi: 10.1186/1471-2121-9-70

Bae, J. S., Koo, N. Y., Namkoong, E., Davies, A. J., Choi, S. K., Shin, Y., et al. (2013). Chaperone stress 70 protein (STCH) binds and regulates two acid/base transporters NBCe1-B and NHE1. J. Biol. Chem. 288, 6295-6305. doi: 10.1074/jbc.M112.392001

Baines, A. J., Lu, H. C., and Bennett, P. M. (2014). The Protein 4.1 family: hub proteins in animals for organizing membrane proteins. Biochim. Biophys. Acta 1838, 605-619. doi: 10.1016/j.bbamem.2013.05.030

Balla, T. (2013). Phosphoinositides: tiny lipids with giant impact on cell regulation. Physiol. Rev. 93, 1019-1137. doi: 10.1152/physrev.00028.2012

Barneaud-Rocca, D., Etchebest, C., and Guizouarn, H. (2013). Structural model of the anion exchanger 1 (SLC4A1) and identification of transmembrane segments forming the transport site. J. Biol. Chem. 288, 26372-26384. doi: 10.1074/jbc.M113.465989

Boedtkjer, E., Praetorius, J., Matchkov, V. V., Stankevicius, E., Mogensen, S., Füchtbauer, A. C., et al. (2011). Disruption of $\mathrm{Na}^{+}, \mathrm{HCO}_{3}^{-}$cotransporter NBCn1 (slc4a7) inhibits NO-mediated vasorelaxation, smooth muscle $\mathrm{Ca}^{2+}$ sensitivity, and hypertension development in mice. Circulation 124, 1819-1829. doi: 10.1161/CIRCULATIONAHA.110.015974

Bok, D., Galbraith, G., Lopez, I., Woodruff, M., Nusinowitz, S., BeltrandelRio, H., et al. (2003). Blindness and auditory impairment caused by loss of the sodium bicarbonate cotransporter NBC3. Nat. Genet. 34, 313-319. doi: 10.1038/ng1176

Boron, W. F. (2012). “Acid-base physiology," in Medical Physiology, 2nd Edn, eds W. F. Boron and E. L. Boulpaep (Philadelphia, PA: Saunders), 652-671.

Boron, W. F., and Boulpaep, E. L. (1983). Intracellular $\mathrm{pH}$ regulation in the renal proximal tubule of the salamander. Basolateral $\mathrm{HCO}_{3}^{-}$transport. J. Gen. Physiol. 81, 53-94. doi: 10.1085/jgp.81.1.53

Boron, W. F., Chen, L., and Parker, M. D. (2009). Modular structure of sodium-coupled bicarbonate transporters. J. Exp. Biol. 212, 1697-1706. doi: 10.1242/jeb.028563

Camilión de Hurtado, M. C., Alvarez, B. V., Pérez, N. G., and Cingolani, H. E. (1996). Role of an electrogenic $\mathrm{Na}^{+}-\mathrm{HCO}_{3}^{-}$cotransport in determining myocardial $\mathrm{pH}_{\mathrm{i}}$ after an increase in heart rate. Circ. Res. 79, 698-704. doi: 10.1161/01.RES.79.4.698

Camilión de Hurtado, M. C., Pérez, N. G., and Cingolani, H. E. (1995). An electrogenic sodium-bicarbonate cotransport in the regulation of myocardial intracellular pH. J. Mol. Cell. Cardiol. 27, 231-242.

Campanella, M. E., Chu, H., Wandersee, N. J., Peters, L. L., Mohandas, N., Gilligan, D. M., et al. (2008). Characterization of glycolytic enzyme interactions with murine erythrocyte membranes in wild-type and membrane protein knockout mice. Blood 112, 3900-3906. doi: 10.1182/blood-2008-03-1 46159

Ch'en, F. F., Villafuerte, F. C., Swietach, P., Cobden, P. M., and VaughanJones, R. D. (2008). S0859, an N-cyanosulphonamide inhibitor of sodiumbicarbonate cotransport in the heart. Br. J. Pharmacol. 153, 972-982. doi: 10.1038/sj.bjp.0707667

Chasis, J., and Mohandas, N. (1992). Red blood cell glycophorins. Blood 80, 1869-1879.
Chesler, M. (2003). Regulation and modulation of $\mathrm{pH}$ in the brain. Physiol. Rev. 83, 1183-1221. doi: 10.1152/physrev.00010.2003

Chu, H., and Low, P. S. (2006). Mapping of glycolytic enzyme-binding sites on human erythrocyte band 3. Biochem. J. 400, 143-151. doi: 10.1042/BJ200 60792

Cooper, G. J., and Fong, P. (2003). Relationship between intracellular pH and chloride in Xenopus oocytes expressing the chloride channel ClC-0. Am. J. Physiol. Cell. Physiol. 284, C331-C338. doi: 10.1152/ajpcell.00406.2002

Coppola, S., and Frömter, E. (1994). An electrophysiological study of angiotensin II regulation of $\mathrm{Na}-\mathrm{HCO}_{3}$ cotransport and $\mathrm{K}$ conductance in renal proximal tubules-I. Effect of picomolar concentrations. Pflügers Arch. Eur. J. Physiol. 427, 143-150. doi: 10.1007/BF00585953

Cordat, E., and Reithmeier, R. A. (2014). "Structure, function, and trafficking of SLC4 and SLC26 anion transporters," in Current Topics in Membranes, Vol. 73, ed M. O. Bevensee (Waltham, MA: Academic Press), 1-67.

Damkier, H. H., Aalkjaer, C., and Praetorius, J. (2010). $\mathrm{Na}^{+}$-dependent $\mathrm{HCO}_{3}^{-}$ import by the slc4a10 gene product involves $\mathrm{Cl}^{-}$export. J. Biol. Chem. 285, 26998-27007. doi: 10.1074/jbc.M110.108712

Danielsen, A. A., Parker, M. D., Lee, S., Boron, W. F., Aalkjaer, C., and Boedtkjer, E. (2013). Splice cassette II of $\mathrm{Na}^{+}, \mathrm{HCO}_{3}^{-}$cotransporter NBCn1 (slc4a7) interacts with calcineurin $\mathrm{A}$ : implications for transporter activity and intracellular $\mathrm{pH}$ control during rat artery contractions. J. Biol. Chem. 288, 8146-8155. doi: 10.1074/jbc.M113.455386

Dart, C., and Vaughan-Jones, R. D. (1992). $\mathrm{Na}^{+}-\mathrm{HCO}_{3}^{-}$symport in the sheep cardiac Purkinje fibre. J. Physiol. 451, 365-385. doi: 10.1113/jphysiol.1992.sp019169

De Giusti, V. C., Orlowski, A., Villa-Abrille, M. C., de Cingolani, G. E., Casey, J. R., Alvarez, B. V., et al. (2011). Antibodies against the cardiac sodium/bicarbonate co-transporter (NBCe1) as pharmacological tools. Br. J. Pharmacol. 164, 1976-1989. doi: 10.1111/j.1476-5381.2011.01496.x

Devogelaere, B., Beullens, M., Sammels, E., Derua, R., Waelkens, E., van Lint, J., et al. (2007). Protein phosphatase-1 is a novel regulator of the interaction between IRBIT and the inositol 1,4,5-trisphosphate receptor. Biochem. J. 407, 303-311. doi: 10.1042/BJ20070361

Di Paolo, G., and De Camilli, P. (2006). Phosphoinositides in cell regulation and membrane dynamics. Nature 443, 651-657. doi: 10.1038/nature05185

Ehret, G. B., Munroe, P. B., Rice, K. M., Bochud, M., Johnson, A. D., Chasman, D. I., et al. (2011). Genetic variants in novel pathways influence blood pressure and cardiovascular disease risk. Nature 478, 103-109. doi: 10.1038/nature10405

Eiam-Ong, S., Hilden, S. A., Johns, C. A., and Madias, N. E. (1993). Stimulation of basolateral $\mathrm{Na}^{+}-\mathrm{HCO}_{3}^{-}$cotransporter by angiotensin II in rabbit renal cortex. Am. J. Physiol. 265, F195-F203.

Fairbanks, G., Steck, T. L., and Wallach, D. F. (1971). Electrophoretic analysis of the major polypeptides of the human erythrocyte membrane. Biochemistry 10 , 2606-2617. doi: 10.1021/bi00789a030

Fantinelli, J. C., Orlowski, A., Aiello, E. A., and Mosca, S. M. (2014). The electrogenic cardiac sodium bicarbonate co-transporer (NBCe1) contributes to the reperfusion injury. Cardovasc. Pathol. 23, 224-230. doi: 10.1016/j.carpath.2014.03.003

Gamper, N., Reznikov, V., Yamada, Y., Yan, J., and Shapiro, M. S. (2004). Phosphotidylinositol 4,5-bisphosphate signals underlie receptor-specific $\mathrm{G}_{\mathrm{q} / 11^{-}}$ mediated modulation of N-type $\mathrm{Ca}^{2+}$ channels. J. Neurosci. 24, 10980-10992. doi: 10.1523/JNEUROSCI.3869-04.2004

Garnett, J. P., Hickman, E., Burrows, R., Hegyi, P., Tiszlavicz, L., Cuthbert, A. W., et al. (2011). Novel role for pendrin in orchestrating bicarbonate secretion in cystic fibrosis transmembrane conductance regulator (CFTR)expressing airway serous cells. J. Biol. Chem. 286, 41069-41082. doi: 10.1074/jbc.M111.266734

Geibel, J., Giebisch, G., and Boron, W. F. (1990). Angiotensin II stimulates both $\mathrm{Na}^{+}-\mathrm{H}^{+}$exchange and $\mathrm{Na}^{+} / \mathrm{HCO}_{3}^{-}$cotransport in the rabbit proximal tubule. Proc. Natl. Acad. Sci. U.S.A. 87, 7917-7920. doi: 10.1073/pnas.87.20.7917

Gill, H. S., and Boron, W. F. (2006). Preliminary X-ray diffraction analysis of the cytoplasmic N-terminal domain of the $\mathrm{Na} / \mathrm{HCO}_{3}$ cotransporter NBCe1A. Acta Crystallogr. Sect. F Struct. Biol. Cryst. Commun. 62, 534-537. doi: 10.1107/S1744309106015181

Gill, H. S., Roush, E. D., Dutcher, L., and Patel, S. (2014). Direct evidence for calcineurin binding to the exon-7 loop of the sodium-bicarbonate cotransporter NBCn1. Int. J. Biol. Sci. 10, 771-776. doi: 10.7150/ijbs.9539 
Grichtchenko, I. I., and Boron, W. F. (2002). Surface-pH measurements in voltageclamped Xenopus oocytes co-expressing NBCe1 and CAIV: evidence for $\mathrm{CO}_{3}^{2-}$ transport (Abstract). FASEB J. 16, A795.

Grichtchenko, I. I., and Chesler, M. (1994). Depolarization-induced acid secretion in gliotic hippocampal slices. Neuroscience 62, 1057-1070. doi: 10.1016/03064522(94)90343-3

Gross, E., Fedotoff, O., Pushkin, A., Abuladze, N., Newman, D., and Kurtz, I. (2003). Phosphorylation-induced modulation of pNBC1 function: distinct roles for the amino- and carboxy-termini. J. Physiol. 549, 673-682. doi: 10.1113/jphysiol.2003.042226

Gross, E., Hawkins, K., Abuladze, N., Pushkin, A., Cotton, C. U., Hopfer, U., et al. (2001a). The stoichiometry of the electrogenic sodium bicarbonate cotransporter NBC1 is cell-type dependent. J. Physiol. 531, 597-603. doi: 10.1111/j.1469-7793.2001.0597h.x

Gross, E., Hawkins, K., Pushkin, A., Sassani, P., Dukkipati, R., Abuladze, N., et al. (2001b). Phosphorylation of Ser ${ }^{982}$ in the sodium bicarbonate cotransporter $\mathrm{kNBC} 1$ shifts the $\mathrm{HCO}_{3}^{-}: \mathrm{Na}^{+}$stoichiometry from 3:1 to 2:1 in murine proximal tubule cells. J. Physiol. 537, 659-665. doi: 10.1113/jphysiol.2001.012956

Gross, E., Pushkin, A., Abuladze, N., Fedotoff, O., and Kurtz, I. (2002). Regulation of the sodium bicarbonate cotransporter $\mathrm{kNBC1}$ function: role of $\mathrm{Asp}^{986}$, $\mathrm{Asp}^{988}$ and kNBC1-carbonic anhydrase II binding. J. Physiol. 544, 679-685. doi: 10.1113/jphysiol.2002.029777

Groves, J. D., and Tanner, M. J. A. (1992). Glycophorin A facilitates the expression of human band 3-mediated anion transport in Xenopus oocytes. J. Biol. Chem. $267,22163-22170$.

Groves, J. D., and Tanner, M. J. A. (1994). The effects of glycophorin A on the expression of the human red cell anion transporter (band 3) in Xenopus oocytes. J. Membr. Biol. 140, 81-88. doi: 10.1007/BF00234488

Gurnett, C. A., Veile, R., Zempel, J., Blackburn, L., Lovett, M., and Bowcock, A. (2008). Disruption of sodium bicarbonate transporter SLC4A10 in a patient with complex partial epilepsy and mental retardation. Arch. Neurol. 65, 550-553. doi: 10.1001/archneur.65.4.550

Hallows, K. R., and Knauf, P. A. (1994). "Principles of cell volume regulation," in Cellular and Molecular Physiology of Cell Volume, ed K. Strange (Boca Raton, FL: CRC Press), 3-29.

Hansen, S. B., Tao, X., and MacKinnon, R. (2011). Structural basis of PIP 2 activation of the classical inward rectifier $\mathrm{K}^{+}$channel Kir2.2. Nature 477, 495-498. doi: 10.1038/nature10370

Hassoun, H., Hanada, T., Lutchman, M., Sahr, K. E., Palek, J., Hanspal, M., et al. (1998). Complete deficiency of glycophorin A in red blood cells from mice with targeted inactivation of the band 3 (AE1) gene. Blood 91, 2146-2151.

He, G., Wang, H. R., Huang, S. K., and Huang, C. L. (2007). Intersectin links WNK kinases to endocytosis of ROMK1. J. Clin. Invest. 117, 1078-1087. doi: $10.1172 /$ JCI30087

Heise, C. J., Xu, B. E., Deaton, S. L., Cha, S. K., Cheng, C. J., Earnest, S., et al. (2010). Serum and glucocorticoid-induced kinase (SGK) 1 and the epithelial sodium channel are regulated by multiple with no lysine (WNK) family members. J. Biol. Chem. 285, 25161-25167. doi: 10.1074/jbc.M110.103432

Heyer, M., Müller-Berger, S., Romero, M. F., Boron, W. F., and Frömter, E. (1999). Stoichiometry of the rat kidney $\mathrm{Na}^{+}-\mathrm{HCO}_{3}^{-}$cotransporter expressed in Xenopus laevis oocytes. Pflügers Arch. Eur. J. Physiol. 438, 322-329. doi: $10.1007 / \mathrm{s} 004240050916$

Hilgemann, D. W., Feng, S., and Nasuhoglu, C. (2001). The complex and intriguing lives of $\mathrm{PIP}_{2}$ with ion channels and transporters. Sci. STKE 111:re19. doi: 10.1126/stke.2001.111.re19

Hirai, T., Hamasaki, N., Yamaguchi, T., and Ikeda, Y. (2011). Topology models of anion exchanger 1 that incorporate the anti-parallel V-shaped motifs found in the EM structure. Biochem. Cell Biol. 89, 148-156. doi: 10.1139/O $10-160$

Hong, J. J. H., Yang, D., Shcheynikov, N., Ohana, E., Shin, D. M., and Muallem, S. (2013). Convergence of IRBIT, phosphatidylinositol $(4,5)$ bisphosphate, and WNK/SPAK kinases in regulation of the $\mathrm{Na}^{+}-\mathrm{HCO}_{3}^{-}$cotransporters family. Proc. Natl. Acad. Sci. U.S.A. 110, 4105-4110. doi: 10.1073/pnas. 1221410110

Ishiguro, H., Steward, M. C., Lindsay, A. R. G., and Case, R. M. (1996a). Accumulation of intracellular $\mathrm{HCO}_{3}^{-}$by $\mathrm{Na}^{+}-\mathrm{HCO}_{3}^{-}$cotransport in interlobular ducts from guinea-pig pancreas. J. Physiol. 495, 169-178. doi: 10.1113/jphysiol.1996.sp021582
Ishiguro, H., Steward, M. C., Wilson, R. W., and Case, R. M. (1996b). Bicarbonate secretion in interlobular ducts from guinea-pig pancreas. J. Physiol. 495, 179-191. doi: 10.1113/jphysiol.1996.sp021583

Jacobs, S., Ruusuvuori, E., Sipilä, S. T., Haapanen, A., Damkier, H. H., Kurth, I., et al. (2008). Mice with targeted Slc4a10 gene disruption have small brain ventricles and show reduced neuronal excitability. Proc. Natl. Acad. Sci. U.S.A. 105, 311-316. doi: 10.1073/pnas. 0705487105

Jalimarada, S. S., Ogando, D. G., Vithana, E. N., and Bonanno, J. A. (2013). Ion transport function of SLC4A11 in corneal endothelium. Invest. Ophthalmol. Vis. Sci. 54, 4330-4340. doi: 10.1167/iovs.13-11929

Jennings, M. L., and Adame, M. F. (1996). Characterization of oxalate transport by the human erythrocyte band 3 protein. J. Gen. Physiol. 107, 145-159. doi: 10.1085/jgp.107.1.145

Jöns, T., and Drenckhahn, D. (1992). Identification of the binding interface involved in linkage of cytoskeletal protein 4.1 to the erythrocyte anion exchanger. EMBO J. 11, 2863-2867.

Jorgensen, P. L., Hakansson, K. O., and Karlish, S. J. (2003). Structure and mechanism of Na,K-ATPase: functional sites and their interactions. Annu. Rev. Physiol. 65, 817-849. doi: 10.1146/annurev.physiol.65.092101.142558

Kao, L., Azimov, R., Abuladze, N., Newman, D., and Kurtz, I. (2014). Human SLC4A11-C Functions as a DIDS-stimulatable $\mathrm{H}^{+}\left(\mathrm{OH}^{-}\right)$permeation pathway: partial correction of R109H mutant transport. Am. J. Physiol. Cell Physiol. 308, C176-C188. doi: 10.1152/ajpcell.00271.2014

Khandoudi, N., Albadine, J., Robert, P., Krief, S., Berrebi-Bertrand, I., Martin, X., et al. (2001). Inhibition of the cardiac electrogenic sodium bicarbonate cotransporter reduces ischemic injury. Cardiovasc. Res. 52, 387-396. doi: 10.1016/S0008-6363(01)00430-8

Kopito, R. R., and Lodish, H. F. (1985). Primary structure and transmembrane orientation of the murine anion exchange protein. Nature 316, 234-238. doi: $10.1038 / 316234 \mathrm{a} 0$

Kudrycki, K. E., Newman, P. R., and Shull, G. E. (1990). cDNA cloning and tissue distribution of mRNAs for two proteins that are related to the band 3 $\mathrm{Cl}^{-} / \mathrm{HCO}_{3}^{-}$exchanger. J. Biol. Chem. 265, 462-471.

Kunimi, M., Seki, G., Hara, C., Taniguchi, S., Uwatoko, S., Goto, A., et al. (2000). Dopamine inhibits renal $\mathrm{Na}^{+}: \mathrm{HCO}_{3}^{-}$cotransporter in rabbits and normotensive rats but not in spontaneously hypertensive rats. Kidney Int. 57, 534-543. doi: 10.1046/j.1523-1755.2000.00873.x

Kurtz, I., and Zhu, Q. (2013a). Proximal renal tubular acidosis mediated by mutations in NBCe1-A: unraveling the transporter's structure-functional properties. Front. Physiol. 4:350. doi: 10.3389/fphys.2013.00350

Kurtz, I., and Zhu, Q. (2013b). Structure, function, and regulation of the SLC4 NBCel transporter and its role in causing proximal renal tubular acidosis. Curr. Opin. Nephrol. Hypertens. 22, 572-583. doi: 10.1097/MNH.0b013e328363ff43

Lagadic-Gossmann, D., Buckler, K. J., and Vaughan-Jones, R. D. (1992). Role of bicarbonate in $\mathrm{pH}$ recovery from intracellular acidosis in the guinea-pig ventricular myocyte. J. Physiol. 458, 361-384. doi: 10.1113/jphysiol.1992.sp019422

Lee, H. J., Kwon, M. H., Lee, S., Hall, R. A., Yun, C. C., and Choi, I. (2014). Systematic family-wide analysis of sodium bicarbonate cotransporter NBCn1/SLC4A7 interactions with PDZ scaffold proteins. Physiol. Rep. 2, 1-11. doi: 10.14814/phy2.12016

Lee, M. G., Ohana, E., Park, H. W., Yang, D., and Muallem, S. (2012a). Molecular mechanism of pancreatic and salivary gland fluid and $\mathrm{HCO}_{3}^{-}$secretion. Physiol. Rev. 92, 39-74. doi: 10.1152/physrev.00011.2011

Lee, S., Yang, H. S., Kim, E., Ju, E. J., Kwon, M. H., Dudley, R. K., et al. (2012b). PSD-95 interacts with $\mathrm{NBCn} 1$ and enhances channel-like activity without affecting $\mathrm{Na} / \mathrm{HCO}_{3}$ cotransport. Cell. Physiol. Biochem. 30, 1444-1455. doi: $10.1159 / 000343332$

Lee, S. K., Boron, W. F., and Parker, M. D. (2012c). Relief of autoinhibition of the electrogenic $\mathrm{Na}-\mathrm{HCO}_{3}$ cotransporter NBCe1-B: role of IRBIT vs. amino-terminal truncation. Am. J. Physiol. Cell Physiol. 302, C518-C526. doi: 10.1152/ajpcell.00352.2011

Lee, S. K., Grichtchenko, I. I., and Boron, W. F. (2011). Distinguishing $\mathrm{HCO}_{3}^{-}$from $\mathrm{CO}_{3}^{2-}$ transport by NBCe1-A (Abstract). FASEB J. 25, 656-659.

Lee, Y. S., Ouyang, Y. B., and Giffard, R. G. (2006). Regulation of the rat brain $\mathrm{Na}^{+}$-driven $\mathrm{Cl}^{-} / \mathrm{HCO}_{3}^{-}$exchanger involves protein kinase $\mathrm{A}$ and a multiprotein signaling complex. FEBS Lett. 580, 4865-4871. doi: 10.1016/j.febslet.2006.07.075 
Leem, C. H., Lagadic-Gossmann, D., and Vaughan-Jones, R. D. (1999). Characterization of intracellular $\mathrm{pH}$ regulation in the guinea-pig ventricular myocyte. J. Physiol. 517, 159-180.

Leviel, F., Hübner, C. A., Houillier, P., Morla, L., El Moghrabi, S., Brideau, G., et al. (2010). The $\mathrm{Na}^{+}$-dependent chloride-bicarbonate exchanger SLC4A8 mediates an electroneutral $\mathrm{Na}^{+}$reabsorption process in the renal cortical collecting ducts of mice. J. Clin. Invest. 120, 1627-1635. doi: 10.1172/JCI40145

Liu, F. Y., and Cogan, M. G. (1989). Angiotensin II stimulates early proximal bicarbonate absorption in the rat by decreasing cyclic adenosine monophosphate. J. Clin. Invest. 84, 83-91. doi: 10.1172/JCI114174

Liu, Y., Qin, X., Wang, D. K., Guo, Y. M., Gill, H. S., Morris, N., et al. (2013). Effects of optional structural elements, including two alternative amino termini and a new splicing cassette IV, on the function of the sodiumbicarbonate cotransporter NBCn1 (SLC4A7). J. Physiol. 591, 4983-5004. doi: 10.1113/jphysiol.2013.258673

Loiselle, F. B., Morgan, P. E., Alvarez, B. V., and Casey, J. R. (2004). Regulation of the human $\mathrm{NBC} 3 \mathrm{Na}^{+/} \mathrm{HCO}_{3}^{-}$cotransporter by carbonic anhydrase II and PKA. Am. J. Physiol. Cell Physiol. 286, C1423-C1433. doi: 10.1152/ajpcell.00382.2003

Lopez, I. A., Acuna, D., Galbraith, G., Bok, D., Ishiyama, A., Liu, W., et al. (2005). Time course of auditory impairment in mice lacking the electroneutral sodium bicarbonate cotransporter NBC3 (slc4a7). Dev. Brain Res. 160, 63-77. doi: 10.1016/j.devbrainres.2005.08.008

Lu, J., Daly, C. M., Parker, M. D., Gill, H. S., Piermarini, P. M., Pelletier, M. F., et al. (2006). Effect of human carbonic anhydrase II on the activity of the human electrogenic $\mathrm{Na} / \mathrm{HCO}_{3}$ cotransporter NBCe1-A in Xenopus oocytes. J. Biol. Chem. 281, 19241-19250. doi: 10.1074/jbc.M602181200

$\mathrm{Lu}$, Z. (2004). Mechanism of rectification in inward-rectifier $\mathrm{K}^{+}$channels. Annu. Rev. Physiol. 66, 103-129. doi: 10.1146/annurev.physiol.66.032102. 150822

Majumdar, D. (2009). Localization and Function of Electrogenic Na/Bicarbonate Cotransporter NBCe1 in Rat Brain. Ph.D. dissertation, University of Alabama at Birmingham.

Majumdar, D., and Bevensee, M. O. (2010). Na-coupled bicarbonate transporters of the solute carrier 4 family in the nervous system: function, localization, and relevance to neurologic function. Neuroscience 171, 951-972. doi: 10.1016/j.neuroscience.2010.09.037

McAlear, S. D., and Bevensee, M. O. (2004). " $\mathrm{pH}$ regulation in non-neuronal brain cells and interstitial fluid," in Non-neuronal Cells of the Nervous System: Function and Dysfunction, ed L. Hertz (Amsterdam: Elsevier Science), 707-745.

McAlear, S. D., and Bevensee, M. O. (2006). A cysteine-scanning mutagenesis study of transmembrane domain 8 of the electrogenic sodium/bicarbonate cotransporter NBCe1. J. Biol. Chem. 281, 32417-32427. doi: 10.1074/jbc.M607253200

McAlear, S. D., Liu, X., Williams, J. B., McNicholas-Bevensee, C. M., and Bevensee, M. O. (2006). Electrogenic $\mathrm{Na} / \mathrm{HCO}_{3}$ cotransporter (NBCe1) variants expressed in Xenopus oocytes: functional comparison and roles of the amino and carboxy termini. J. Gen. Physiol. 127, 639-658. doi: 10.1085/jgp.200609520

McKinney, T. D., and Myers, P. (1980). Bicarbonate transport by proximal tubules: effect of parathyroid hormone and dibutyryl cyclic AMP. Am. J. Physiol. 238, F166-F174.

Milanick, M. A., and Gunn, R. B. (1984). Proton-sulfate cotransport: external proton activation of sulfate influx into human red blood cells. Am. J. Physiol. 247, C247-C259.

Moss, F. J., Seong, L., Parker, M. D., and Boron, W. F. (2014). Distinguishing $\mathrm{HCO}_{3}^{-}$from $\mathrm{CO}_{3}^{2-}$ transport by the electrogenic $\mathrm{Na} / \mathrm{HCO}_{3}$ cotransporter NBCe1 (SLC4A4) (Abstract). FASEB. J. 28, 1098.7.

Muallem, S., and Loessberg, P. A. (1990). Intracellular pH-regulatory mechanisms in pancreatic acinar cells. I. Characterization of $\mathrm{H}^{+}$and $\mathrm{HCO}_{3}^{-}$transporters. J. Biol. Chem. 265, 12806-12812.

Müller-Berger, S., Ducoudret, O., Diakov, A., and Frömter, E. (2001). The renal $\mathrm{Na}-\mathrm{HCO}_{3}$-cotransporter expressed in Xenopus laevis oocytes: change in stoichiometry in response to elevation of cytosolic $\mathrm{Ca}^{2+}$ concentration. Pflügers Arch. Eur. J. Physiol. 442, 718-728. doi: 10.1007/s004240100592

Murphy, E., Steenbergen, C., Levy, L. A., Raju, B., and London, R. E. (1989). Cysofolic free magnesium levels in ischemic rat heart. J. Biol. Chem. 264, 5622-5627.
No, Y. R., He, P., Yoo, B. K., and Yun, C. C. (2015). Regulation of NHE3 by lysophosphatidic acid is mediated by phosphorylation of NHE3 by RSK2. Am. J. Physiol. Cell Physiol. doi: 10.1152/ajpcell.00067.2015. [Epub ahead of print].

Ogando, D. G., Jalimarada, S. S., Zhang, W., Vithana, E. N., and Bonanno, J. A. (2013). SLC4A11 is an EIPA-sensitive $\mathrm{Na}^{+}$permeable $\mathrm{pH}_{\mathrm{i}}$ regulator. Am. J. Physiol. Cell Physiol. 305, C716-C727. doi: 10.1152/ajpcell.00056.2013

Park, S., Hong, J. H., Ohana, E., and Muallem, S. (2012). The WNK/SPAK and IRBIT/PP1 pathways in epithelial fluid and electrolyte transport. Physiology 27, 291-299. doi: 10.1152/physiol.00028.2012

Parker, M. D., and Boron, W. F. (2013). The divergence, actions, roles, and relatives of sodium-coupled bicarbonate transporters. Physiol. Rev. 93, 803-959. doi: 10.1152/physrev.00023.2012

Parker, M. D., Bouyer, P., Daly, C. M., and Boron, W. F. (2008). Cloning and characterization of novel human SLC4A8 gene products encoding $\mathrm{Na}^{+}$-driven $\mathrm{Cl}^{-} / \mathrm{HCO}_{3}^{-}$exchanger variants NDCBE-A, -C, and -D. Physiol. Genomics. 34, 265-276. doi: 10.1152/physiolgenomics.90259.2008

Parker, M. D., Daly, C. M., Skelton, L. A., and Boron, W. F. (2007a). IRBIT functionally enhances the electroneutral $\mathrm{Na}$-coupled bicarbonate transporter NCBE by sequestering an N-terminal autoinhibitory domain (Abstract). FASEB J. 21, A1285.

Parker, M. D., Skelton, L. A., Daly, C. M., and Boron, W. F. (2007b). IRBIT binds to and functionally enhances the electroneutral Na-coupled bicarbonate transporters NBCn1, NDCBE and NCBE (Abstract). FASEB J. 21, A1285.

Pasternack, G. R., Anderson, R. A., Leto, T. L., and Marchesi, V. T. (1985). Interactions between protein 4.1 and band 3. An alternative binding site for an element of the membrane skeleton. J. Biol. Chem. 260, 3676-3683.

Perry, C., Baker, O. J., Reyland, M. E., and Grichtchenko, I. I. (2009). PKC $\alpha \beta \gamma$ and PKC $\delta$-dependent endocytosis of NBCe1-A and NBCe1-B in salivary parotid acinar cells. Am. J. Physiol. Cell Physiol. 297, C1409-C1423. doi: 10.1152/ajpcell.00028.2009

Perry, C., Blaine, J., Le, H., and Grichtchenko, I. I. (2006). PMA- and ANG IIinduced PKC regulation of the renal $\mathrm{Na}^{+}-\mathrm{HCO}_{3}^{-}$cotransporter (hkNBCe1). Am. J. Physiol. Renal Physiol. 290, F417-F427. doi: 10.1152/ajprenal.0039 5.2004

Perry, C., Le, H., and Grichtchenko, I. I. (2007). ANG II and calmodulin/CaMKII regulate surface expression and functional activity of NBCel via separate means. Am. J. Physiol. Renal Physiol. 293, F68-F77. doi: 10.1152/ajprenal.00454.2006

Piermarini, P. M., Kim, E. Y., and Boron, W. F. (2007). Evidence against a direct interaction between intracellular carbonic anhydrase II and pure C-terminal domains of SLC4 bicarbonate transporters. J. Biol. Chem. 282, 1409-1421. doi: 10.1074/jbc.M608261200

Pushkin, A., Abuladze, N., Gross, E., Newman, D., Tatishchev, S., Lee, I., et al. (2004). Molecular mechanism of kNBC1-carbonic anhydrase II interaction in proximal tubule cells. J. Physiol. 559, 55-65. doi: 10.1113/jphysiol.2004. 065110

Reithmeier, R. A., Chan, S., and Popov, M. (1996). "Structure of the erythrocyte band 3 anion exchanger," in Handbook of Biological Physics, eds W. Konings, H. Kaback, and J. Lolkema (Amsterdam: Elsevier B.V.), 281-309.

Richards, S. M., Jaconi, M. E., Vassort, G., and Pucéat, M. (1999). A spliced variant of AE1 gene encodes a truncated form of Band 3 in heart: the predominant anion exchanger in ventricular myocytes. J. Cell Sci. 112, 1519-1528.

Robey, R. B., Ruiz, O. S., Espiritu, D. J. D., Ibañez, V. C., Kear, F. T., Noboa, O. A., et al. (2002). Angiotensin II stimulation of renal epithelial cell $\mathrm{Na} / \mathrm{HCO}_{3}$ cotransport activity: a central role for Src family kinase/classic MAPK pathway coupling. J. Membr. Biol. 187, 135-145.

Romani, A. (2007). Regulation of magnesium homeostasis and transport in mammalian cells. Arch. Biochem. Biophys. 458, 90-102. doi: 10.1016/j.abb.2006.07.012

Romero, M. F., Fulton, C. M., and Boron, W. F. (2004). The SLC4 family of $\mathrm{HCO}_{3}^{-}$ transporters. Pflügers Arch. Eur. J. Physiol. 447, 495-509. doi: 10.1007/s00424003-1180-2

Romero, M. F., Hediger, M. A., Boulpaep, E. L., and Boron W. F. (1997). Expression cloning and characterization of a renal electrogenic $\mathrm{Na}^{+} / \mathrm{HCO}_{3}^{-}$cotransporter. Nature 387, 409-413. doi: 10.1038/387409a0

Ruiz, O. S., Qiu, Y. Y., Wang, L. J., and Arruda, J. A. L. (1995). Regulation of the renal $\mathrm{Na}-\mathrm{HCO}_{3}$ cotransporter: IV. Mechanisms of the stimulatory effect of angiotensin II. J. Am. Soc. Nephrol. 6, 1202-1208. 
Rusnak, F., and Mertz, P. (2000). Calcineurin: form and function. Physiol. Rev. 80, 1483-1521. Available online at: http://physrev.physiology.org/content/80/ $4 / 1483$

Sawasdee, N., Junking, M., Ngaojanlar, P., Sukomon, N., Ungsupravate, D., Limjindaporn, T., et al. (2010). Human kidney anion exchanger 1 interacts with adaptor-related protein complex $1 \mu 1 \mathrm{~A}(\mathrm{AP}-1 \mu 1 \mathrm{~A})$. Biochem. Biophys. Res. Commun. 401, 85-91. doi: 10.1016/j.bbrc.2010.09.015

Schafer, C., Ladilov, Y. V., Siegmund, B., and Piper, H. M. (2000). Importance of bicarbonate transport for protection of cardiomyocytes against reoxygenation injury. Am. J. Physiol. Heart Circ. Physiol. 278, H1457-H1463. Available online at: http://ajpheart.physiology.org/content/278/5/H1457

Schueler, C., Becker, H. M., McKenna, R., and Deitmer, J. W. (2011). Transport activity of the sodium bicarbonate cotransporter NBCe1 is enhanced by different isoforms of carbonic anhydrase. PLOS ONE 6:e27167. doi: 10.1371/journal.pone. 0027167

Sciortino, C. M., and Romero, M. F. (1999). Cation and voltage dependence of rat kidney electrogenic $\mathrm{Na}^{+}-\mathrm{HCO}_{3}^{-}$cotransporter, rkNBC, expressed in oocytes. Am. J. Physiol. 277, F611-F623.

Seki, G., Yamada, H., Horita, S., Suzuki, M., Sekine, T., Igarashi, T., et al. (2008). Activation and inactivation mechanisms of $\mathrm{Na}-\mathrm{HCO}_{3}$ cotransporter $\mathrm{NBC}$. J. Epithel. Biol. Pharmacol. 1, 35-39. doi: 10.2174/1875044300801010035

Shan, J., Liao, J., Huang, J., Robert, R., Palmer, M. L., Fahrenkrug, S. C., et al. (2012). Bicarbonate-dependent chloride transport drives fluid secretion by the human airway epithelial cell line Calu-3. J. Physiol. 590, 5273-5297. doi: 10.1113/jphysiol.2012.236893

Shcheynikov, N., Son, A., Hong, J. H., Yamazaki, O., Ohana, E., Kurtz, I., et al. (2015). Intracellular $\mathrm{Cl}^{-}$as a signaling ion that potently regulates $\mathrm{Na}^{+} / \mathrm{HCO}_{3}^{-}$transporters. Proc. Natl. Acad. Sci. U.S.A. 112, E329-E337. doi: 10.1073/pnas.1415673112

Shirakabe, K., Priori, G., Yamada, H., Ando, H., Horita, S., Fujita, T., et al. (2006). IRBIT, an inositol 1, 4, 5-trisphosphate receptor-binding protein, specifically binds to and activates pancreas-type $\mathrm{Na}^{+} / \mathrm{HCO}_{3}^{-}$cotransporter 1 (pNBC1). Proc. Natl. Acad. Sci. U.S.A. 103, 9542-9547. doi: 10.1073/pnas.0602250103

Shnitsar, V., Li, J., Li, X., Calmettes, C., Basu, A., Casey, J. R., et al. (2013). A substrate access tunnel in the cytosolic domain is not an essential feature of the solute carrier 4 (SLC4) family of bicarbonate transporters. J. Biol. Chem. 288, 33848-33860. doi: 10.1074/jbc.M113.511865

Sinning, A., Liebmann, L., Kougioumtzes, A., Westermann, M., Bruehl, C., and Hübner, C. A. (2011). Synaptic glutamate release is modulated by the $\mathrm{Na}^{+}$-driven $\mathrm{Cl}^{-} / \mathrm{HCO}_{3}^{-}$exchanger Slc4a8. J. Neurosci. 31, 7300-7311. doi: 10.1523/JNEUROSCI.0269-11.2011

Soleimani, M., Grassi, S. M., and Aronson, P. S. (1987). Stoichiometry of $\mathrm{Na}^{+}-$ $\mathrm{HCO}_{3}^{-}$cotransport in basolateral membrane vesicles isolated from rabbit renal cortex. J. Clin. Invest. 79, 1276-1280. doi: 10.1172/JCI112948

Sowah, D., and Casey, J. R. (2011). An intramolecular transport metabolon: fusion of carbonic anhydrase II to the $\mathrm{COOH}$ terminus of the $\mathrm{Cl}^{-} / \mathrm{HCO}_{3}^{-}$exchanger, AE1. Am. J. Physiol. Cell Physiol. 301, C336-C346. doi: 10.1152/ajpcell.00005. 2011

Sterling, D., Reithmeier, R. A. F., and Casey, J. R. (2001). A transport metabolon: functional interaction of carbonic anhydrase II and chloride/bicarbonate exchangers. J. Biol. Chem. 276, 47886-47894. doi: 10.1074/jbc.M105959200

Steward, M. C., and Ishiguro, H. (2009). Molecular and cellular regulation of pancreatic duct cell function. Curr. Opin. Gastroenterol. 25, 447-453. doi: 10.1097/MOG.0b013e32832e06ce

Su, Y., Blake-Palmer, K. G., Fry, A. C., Best, A., Brown, A. C. N., Hiemstra, T. F., et al. (2011). Glyceraldehyde 3-phosphate dehydrogenase is required for band 3 (anion exchanger 1) membrane residency in the mammalian kidney. Am. J. Physiol. Renal Physiol. 300, F157-F166. doi: 10.1152/ajprenal. 00228.2010

Suh, B. C., and Hille, B. (2005). Regulation of ion channels by phosphatidylinositol 4,5-bisphosphate. Curr. Opin. Neurobiol. 15, 370-378. doi: 10.1016/j.conb.2005.05.005

Suh, B. C., and Hille, B. (2007). Electrostatic interaction of internal $\mathrm{Mg}^{2+}$ with membrane PIP $_{2}$ seen with KCNQ K ${ }^{+}$channels. J. Gen. Physiol. 130, 241-256. doi: 10.1085/jgp.200709821

Sung, L. A., Chien, S., Fan, Y. S., Lin, C. C., Lambert, K., Zhu, L., et al. (1992). Human erythrocyte protein 4.2 : isoform expression, differential splicing, and chromosomal assignment. Blood 79, 2763-2770.
Svichar, N., Esquenazi, S., Chen, H. Y., and Chesler, M. (2011). Preemptive regulation of intracellular $\mathrm{pH}$ in hippocampal neurons by a dual mechanism of depolarization-induced alkalinization. J. Neurosci. 31, 6997-7004. doi: 10.1523/JNEUROSCI.6088-10.2011

Tanphaichitr, V. S., Sumboonnanonda, A., Ideguchi, H., Shayakul, C., Brugnara, C., Takao, M., et al. (1998). Novel AE1 mutations in recessive distal renal tubular acidosis. Loss-of-function is rescued by glycophorin A. J. Clin. Invest. 102, 2173-2179. doi: 10.1172/JCI4836

Ten Hove, M., Nederhoff, M. G., and Van Echteld, C. J. (2005). Relative contributions of $\mathrm{Na}^{+} / \mathrm{H}^{+}$exchange and $\mathrm{Na}^{+} / \mathrm{HCO}_{3}^{-}$cotransport to ischemic $\mathrm{Na}_{\mathrm{i}}^{+}$overload in isolated rat hearts. Am. J. Physiol. Heart Circ. Physiol. 288, H287-H292. doi: 10.1152/ajpheart.01102.2003

Terada, N., Ohno, N., Saitoh, S., Seki, G., Komada, M., Suzuki, T., et al. (2007). Interaction of membrane skeletal protein, protein $4.1 \mathrm{~B}$ and p55, and sodium bicarbonate cotransporter1 in mouse renal S1-S2 proximal tubules. J. Histochem. Cytochem. 55, 1199-1206. doi: 10.1369/jhc.7A7266.2007

Thornell, I. M., and Bevensee, M. O. (2015). Phosphatidylinositol 4,5-bisphosphate degradation inhibits the $\mathrm{Na}^{+} /$bicarbonate cotransporter NBCe1-B and C variants expressed in Xenopus oocytes. J. Physiol. 593, 541-558. doi: 10.1113/jphysiol.2014.284307

Thornell, I. M., Wu, J., and Bevensee, M. O. (2010). The $\mathrm{IP}_{3}$ receptorbinding protein IRBIT reduces phosphatidylinositol 4,5-bisphosphate $\left(\mathrm{PIP}_{2}\right)$ stimulation of $\mathrm{Na} /$ bicarbonate cotransporter NBCel variants expressed in Xenopus laevis oocytes (Abstract). FASEB J. 24, 815.6.

Thornell, I. M., Wu, J., Liu, X., and Bevensee, M. O. (2012). PIP 2 hydrolysis stimulates electrogenic $\mathrm{Na}^{+}$-bicarbonate cotransporter $\mathrm{NBCe} 1-\mathrm{B}$ and $-\mathrm{C}$ variants expressed in Xenopus laevis oocytes. J. Physiol. 590, 5993-6011. doi: 10.1113/jphysiol.2012.242479

Toye, A. M., Ghosh, S., Young, M. T., Jones, G. K., Sessions, R. B., Ramaugé, M., et al. (2005). Protein-4.2 association with band 3 (AE1, SLCA4) in Xenopus oocytes: effects of three natural protein- 4.2 mutations associated with hemolytic anemia. Blood 105, 4088-4095. doi: 10.1182/blood-200405-1895

van Borren, M. M., Baartscheer, A., Wilders, R., and Ravesloot, J. H. (2004). NHE-1 and NBC during pseudo-ischemia/reperfusion in rabbit ventricular myocytes. J. Mol. Cell. Cardiol. 37, 567-577. doi: 10.1016/j.yjmcc.2004. 05.017

van den Akker, E., Satchwell, T. J., Williamson, R. C., and Toye, A. M. (2010). Band 3 multiprotein complexes in the red cell membrane; of mice and men. Blood Cells. Mol. Dis. 45, 1-8. doi: 10.1016/j.bcmd.2010.02.019

Vandenberg, J. I., Metcalfe, J. C., and Grace, A. A. (1993). Mechanisms of $\mathrm{pH}_{\mathrm{i}}$ recovery after global ischemia in the perfused heart. Circ. Res. 72, 993-1003. doi: 10.1161/01.RES.72.5.993

Villa-Abrille, M. C., Petroff, M. G., and Aiello, E. A. (2007). The electrogenic $\mathrm{Na}^{+} / \mathrm{HCO}_{3}^{-}$cotransport modulates resting membrane potential and action potential duration in cat ventricular myocytes. J. Physiol. 578, 819-829. doi: 10.1113/jphysiol.2006.120170

Vince, J. W., and Reithmeier, R. A. F. (1998). Carbonic anhydrase II binds to the carboxyl terminus of human band 3, the erythrocyte $\mathrm{Cl}^{-} / \mathrm{HCO}_{3}^{-}$exchanger. J. Biol. Chem. 273, 28430-28437. doi: 10.1074/jbc.273.43.28430

Vince, J. W., and Reithmeier, R. A. F. (2000). Identification of the carbonic anhydrase II binding site in the $\mathrm{Cl}^{-} / \mathrm{HCO}_{3}^{-}$anion exchanger AE1. Biochemistry 39, 5527-5533. doi: 10.1021/bi992564p

Voipio, J. (1998). "Diffusion and buffering aspects of $\mathrm{H}^{+}, \mathrm{HCO}_{3}^{-}$, and $\mathrm{CO}_{2}$ movements in brain tissue," in $p H$ and Brain Function, eds K. Kaila and B. R. Ransom (New York, NY: Wiley-Liss), 45-65.

Wang, D. N., Sarabia, V. E., Reithmeier, R. A. F., and Kühlbrandt, W. (1994). Three-dimensional map of the dimeric membrane domain of the human erythrocyte anion exchanger, Band 3. EMBO J. 13, 3230-3235.

Wang, Z., Schultheis, P. J., and Shull, G. E. (1996). Three N-terminal variants of the $\mathrm{AE} 2 \mathrm{Cl}^{-} / \mathrm{HCO}_{3}^{-}$exchanger are encoded by mRNAs transcribed from alternative promoters. J. Biol. Chem. 271, 7835-7843. doi: $10.1074 /$ jbc. 271.13 .7835

Whorton, M. R., and MacKinnon, R. (2011). Crystal structure of the mammalian GIRK2 $\mathrm{K}^{+}$channel and gating regulation by $\mathrm{G}$ proteins, $\mathrm{PIP}_{2}$, and sodium. Cell 147, 199-208. doi: 10.1016/j.cell.2011.07.046

Williamson, R. C., Brown, A. C. N., Mawby, W. J., and Toye, A. M. (2008). Human kidney anion exchanger 1 localisation in MDCK cells is controlled by the 
phosphorylation status of two critical tyrosines. J. Cell Sci. 121, 3422-3432. doi: $10.1242 /$ jcs. 035584

Wilson, F. H., Disse-Nicodème, S., Choate, K. A., Ishikawa, K., Nelson-Williams, C., Desitter, I., et al. (2001). Human hypertension caused by mutations in WNK kinases. Science 293, 1107-1112. doi: 10.1126/science.1062844

Winks, J. S., Hughes, S., Filippov, A. K., Tatulian, L., Abogadie, F. C., Brown, D. A., et al. (2005). Relationship between membrane phosphatidylinositol4,5-bisphosphate and receptor-mediated inhibition of native neuronal $\mathrm{M}$ channels. J. Neurosci. 25, 3400-3413. doi: 10.1523/JNEUROSCI.323104.2005

Wu, F., Saleem, M. A., Kampik, N. B., Satchwell, T. J., Williamson, R. C., Blattner, S. M., et al. (2010). Anion exchanger 1 interacts with nephrin in podocytes. J. Am. Soc. Nephrol. 21, 1456-1467. doi: 10.1681/ASN.2009090921

Wu, J., McNicholas, C. M., and Bevensee, M. O. (2009). Phosphatidylinositol 4,5-bisphosphate $\left(\mathrm{PIP}_{2}\right)$ stimulates the electrogenic $\mathrm{Na} / \mathrm{HCO}_{3}$ cotransporter NBCe1-A expressed in Xenopus oocytes. Proc. Natl. Acad. Sci. U.S.A. 106, 14150-14155. doi: 10.1073/pnas.0906303106

$\mathrm{Xu}, \mathrm{W}$. (2011). PSD-95-like membrane associated guanylate kinases (PSDMAGUKs) and synaptic plasticity. Curr. Opin. Neurobiol. 21, 306-312. doi: 10.1016/j.conb.2011.03.001

Yamaguchi, S., and Ishikawa, T. (2008). The electrogenic $\mathrm{Na}^{+}-\mathrm{HCO}_{3}^{-}$ cotransporter NBCe1-B is regulated by intracellular $\mathrm{Mg}^{2+}$. Biochem. Biophys. Res. Commun. 376, 100-104. doi: 10.1016/j.bbrc.2008.08.104

Yamaguchi, S., and Ishikawa, T. (2012). IRBIT reduces the apparent affinity for intracellular $\mathrm{Mg}^{2+}$ in inhibition of the electrogenic $\mathrm{Na}^{+}-\mathrm{HCO}_{3}^{-}$ cotransporter NBCe1-B. Biochem. Biophys. Res. Commun. 424, 433-438. doi: 10.1016/j.bbrc.2012.06.127

Yamaguchi, T., Ikeda, Y., Abe, Y., Kuma, H., Kang, D., Hamasaki, N., et al. (2010). Structure of the membrane domain of human erythrocyte anion exchanger 1 revealed by electron crystallography. J. Mol. Biol. 397, 179-189. doi: $10.1016 /$ j.jmb.2010.01.027

Yang, C. L., Liu, X., Paliege, A., Zhu, X., Bachmann, S., Dawson, D. C., et al. (2007). WNK1 and WNK4 modulate CFTR activity. Biochem. Biophys. Res. Commun. 353, 535-540. doi: 10.1016/j.bbrc.2006.11.151

Yang, D., Li, Q., So, I., Huang, C. L., Ando, H., Mizutani, A., et al. (2011). IRBIT governs epithelial secretion in mice by antagonizing the WNK/SPAK kinase pathway. J. Clin. Invest. 121, 956-965. doi: 10.1172/JCI43475

Yang, D., Shcheynikov, N., Zeng, W., Ohana, E., So, I., Ando, H., et al. (2009). IRBIT coordinates epithelial fluid and $\mathrm{HCO}_{3}^{-}$secretion by stimulating the transporters $\mathrm{pNBC} 1$ and CFTR in the murine pancreatic duct. J. Clin. Invest. 119, 193-202. doi: 10.1172/JCI36983

Yannoukakos, D., Meyer, H. E., Vasseur, C., Driancourt, C., Wajcman, H., and Bursaux, E. (1991). Three regions of erythrocyte band 3 protein are phosphorylated on tyrosines: characterization of the phosphorylation sites by solid phase sequencing combined with capillary electrophoresis. Biochim. Biophys. Acta 1066, 70-76. doi: 10.1016/0005-2736(91)90252-4

Young, M. T., and Tanner, M. J. A. (2003). Distinct regions of human glycophorin A enhance human red cell anion exchanger (band 3; AE1) transport function and surface trafficking. J. Biol. Chem. 278, 32954-32961. doi: $10.1074 /$ jbc.M302527200

Zaika, O., Zhang, J., and Shapiro, M. S. (2011). Phosphoinositide and $\mathrm{Ca}^{2+}$ signals mediating receptor specificity toward neuronal $\mathrm{Ca}^{2+}$ channels. J. Biol. Chem. 286, 830-841. doi: 10.1074/jbc.M110.166033

Zhang, D., Kiyatkin, A., Bolin, J. T., and Low, P. S. (2000). Crystallographic structure and functional interpretation of the cytoplasmic domain of erythrocyte membrane band 3. Blood 96, 2925-2933. Available online at: http:// www.bloodjournal.org/content/96/9/2925

Zhang, H., Craciun, L. C., Mirshahi, T., Rohács, T., Lopes, C. M. B., Jin, T., et al. (2003). PIP 2 activates KCNQ channels, and its hydrolysis underlies receptor-mediated inhibition of M currents. Neuron. 37, 963-975. doi: 10.1016/S0896-6273(03)00125-9

Zheng, Y., Horita, S., Hara, C., Kunimi, M., Yamada, H., Sugaya, T., et al. (2003). Biphasic regulation of renal proximal bicarbonate absorption by luminal $\mathrm{AT}_{1 \mathrm{~A}}$ receptor. J. Am. Soc. Nephrol. 14, 1116-1122. doi: 10.1097/01.ASN.0000064700.58048.C1

Zhu, Q., Kao, L., Azimov, R., Abuladze, N., Newman, D., Pushkin, A., et al. (2010a). Structural and functional characterization of the C-terminal transmembrane region of NBCe1-A. J. Biol. Chem. 285, 37178-37187. doi: 10.1074/jbc.M110.169201

Zhu, Q., Kao, L., Azimov, R., Newman, D., Liu, W., Pushkin, A., et al. (2010b). Topological location and structural importance of the NBCel-A residues mutated in proximal renal tubular acidosis. J. Biol. Chem. 285, 13416-13426. doi: 10.1074/jbc.M109.093286

Zhu, Q., Shao, X. M., Kao, L., Azimov, R., Weinstein, A. M., Newman, D., et al. (2013). Missense mutation T485S alters NBCe1-A electrogenicity causing proximal renal tubular acidosis. Am. J. Physiol. Cell Physiol. 305, C392-C405. doi: 10.1152/ajpcell.00044.2013

Conflict of Interest Statement: The authors declare that the research was conducted in the absence of any commercial or financial relationships that could be construed as a potential conflict of interest.

Copyright $\odot 2015$ Thornell and Bevensee. This is an open-access article distributed under the terms of the Creative Commons Attribution License (CC BY). The use, distribution or reproduction in other forums is permitted, provided the original author(s) or licensor are credited and that the original publication in this journal is cited, in accordance with accepted academic practice. No use, distribution or reproduction is permitted which does not comply with these terms. 